\title{
Improvement of ERA5 over ERA-Interim in Simulating Surface Incident Solar Radiation throughout China ${ }^{\circ}$
}

\author{
YANYI He, ${ }^{a}$ KaICUN WANG, ${ }^{\text {a }}$ AND FeI Feng ${ }^{\mathrm{b}}$ \\ ${ }^{\text {a }}$ State Key Laboratory of Earth Surface Processes and Resource Ecology, College of Global Change and Earth \\ System Science, Beijing Normal University, Beijing, China \\ ${ }^{\mathrm{b}}$ College of Forestry, Beijing Forestry University, Beijing, China
}

(Manuscript received 27 April 2020, in final form 24 January 2021)

\begin{abstract}
Surface incident solar radiation $\left(R_{s}\right)$ is important for providing essential information on climate change. Existing studies have shown that the $R_{s}$ values from current reanalyses are significantly overestimated throughout China. The European Centre for Medium-Range Weather Forecasts (ECMWF) recently released the fifth generation of atmospheric reanalysis (i.e., ERA5) with a much higher spatiotemporal resolution and a major upgrade compared to its predecessor, ERA-Interim. This study is to verify whether ERA5 can improve the $R_{s}$ simulation using sunshine durationderived $R_{s}$ values at $\sim 2200$ stations over China from 1979 to 2014 as reference data. Compared with the observed multiyear national mean, the $R_{s}$ overestimation is reduced from $15.88 \mathrm{~W} \mathrm{~m}^{-2}$ in ERA-Interim to $10.07 \mathrm{~W} \mathrm{~m}^{-2}$ in ERA5. From 1979 to 1993, ERA-Interim $\left(-1.99 \mathrm{~W} \mathrm{~m}^{-2}\right.$ decade $\left.^{-1} ; p<0.05\right)$ and ERA5 $\left(-2.42 \mathrm{~W} \mathrm{~m}^{-2}\right.$ decade $\left.^{-1} ; p<0.05\right)$ estimates of $R_{s}$ in China continued to decrease and the decline of the latter is closer to the observed. After 1993, they both show a strong brightening (i.e., $2.26 \mathrm{~W} \mathrm{~m}^{-2}$ decade $^{-1}$ in ERA-Interim and $1.49 \mathrm{~W} \mathrm{~m}^{-2}$ decade $^{-1}$ in ERA5) but observations show a nonsignificant increase by $0.30 \mathrm{~W} \mathrm{~m}^{-2} \mathrm{decade}^{-1}$. Due to the improvement of total cloud cover (TCC) simulation by ERA5, its $R_{s}$ trend bias induced by the TCC trend bias is smaller than that in ERA-Interim. In addition, the reason why the simulation trend in ERA5 remains biased might be that ERA5 still ignores aerosol changes on interannual or decadal time scales. Therefore, subsequent reanalysis products still need to improve their simulation of clouds, water vapor, and aerosol, especially in aerosol direct and indirect effects on $R_{s}$.
\end{abstract}

KEYWORDS: Atmosphere-land interaction; Shortwave radiation; Surface observations; Reanalysis data

\section{Introduction}

Surface incident solar radiation $\left(R_{s}\right)$ is one of the key variables of Earth's energy balance to determine our climate. Ground-based observations have revealed a significant decrease in $R_{s}$ from the 1950 s to the 1980 s and a subsequent increase at locations worldwide; these phenomena are colloquially known as global dimming and brightening (Stanhill and Cohen 2001; Wild 2009). In China, the dimming significantly occurred before the 1990s and then leveled off (He and Wang 2019).

Observations of $R_{s}$ have been plagued by a sparse distribution of sites and insufficient maintenance or calibration on relevant instruments (Wild and Schmucki 2010; Wild 2016). In particular for China, ongoing instrument sensitivity drift resulted in spurious $R_{s}$ trends; serious jumps are obviously seen in the observed $R_{s}$ series especially during the period of 1900-93 due to many instrument replacements (Wang and Wild 2016; Yang et al. 2018).

Sunshine duration (SunDu) has been suggested as a proxy of $R_{s}$ (Wild 2009). SunDu observations have a wider spatial coverage and a longer time record back to the late nineteenth century (Wild 2009). SunDu-derived $R_{S}$ data suffer from fewer

Supplemental information related to this paper is available at the Journals Online website: https://doi.org/10.1175/JCLI-D-200300.s1.

Corresponding author: Kaicun Wang, kcwang@bnu.edu.cn inhomogeneity issues compared to the observed $R_{s}$, and have been employed to reveal the monthly, interannual, decadal, and long-term variability of $R_{s}$, even though they have difficulty at shorter time scales (Wild 2009; Tang et al. 2011; Wang 2014; Wang et al. 2015). More importantly, SunDu-derived $R_{\mathrm{s}}$ can also include information on long-term trends of clouds and atmospheric aerosols, thereby reflecting the impacts of both clouds and aerosols (Sanchez-Romero et al. 2014).

Reanalysis products are an important complement containing long-term $R_{s}$ data and hence have been widely used in climate studies (Zhou et al. 2017; Huang et al. 2018; Urraca et al. 2018a; Zhou et al. 2018) due to the dynamically consistent and spatiotemporally complete atmospheric fields with high resolution and open access of data. However, existing studies have shown that reanalysis products generally overestimate multiyear mean $R_{s}$ values compared with observations over land (Kennedy et al. 2011; Zhao et al. 2013; Zhou and Wang 2016). The use of these products, such as the Japanese 55-year Reanalysis (JRA-55), Modern-Era Retrospective Analysis for Research and Applications (MERRA), and European Center for Medium-Range Weather Forecasting (ECMWF) interim reanalysis (ERA-Interim) products, has been questioned in the reproduction of long-term trends (Thorne and Vose 2010; Dee et al. 2011a), probably due to inferior cloud simulations and lack of information on interannual or decadal aerosol variations (Xia et al. 2006; Zhang et al. 2016; Zhou et al. 2018). MERRA version 2 (MERRA-2) still exhibits high national mean bias ( $40.02 \mathrm{~W} \mathrm{~m}^{-2}$ ) and overestimates decreasing trend from 1980 to 2014 in China due to the inclusion of too-strong 
TABLE 1. Summary of ERA5 and ERA-Interim (ERAI). The model name, period, spatial and temporal resolutions, and model information on relevant meteorological factors $\left(R_{s}\right.$, TCC, WVP, and aerosol) are shown.

\begin{tabular}{|c|c|c|c|}
\hline & & ERAI & ERA5 \\
\hline \multicolumn{2}{|c|}{ Assimilation system } & IFS Cycle 31r2 4D-Var & IFS Cycle 41r2 4D-Var \\
\hline \multicolumn{2}{|c|}{ Spatial resolution } & $\sim 79 \mathrm{~km}, 60$ levels to $0.1 \mathrm{hPa}$ & $\sim 31 \mathrm{~km}, 137$ levels to $0.01 \mathrm{hPa}$ \\
\hline \multicolumn{2}{|c|}{ Temporal resolution } & $6 \mathrm{~h}$ & $1 \mathrm{~h}$ \\
\hline \multicolumn{2}{|c|}{ Period } & 1979-2019 & 1950-present \\
\hline \multirow[t]{4}{*}{ Model input } & $R_{s}$ & Six-band shortwave parameterization model & Rapid Radiative Transfer Model shortwave scheme \\
\hline & TCC & $\begin{array}{l}\text { Prognostic scheme based on an equation of the } \\
\text { sources and sinks of cloud areas }\end{array}$ & $\begin{array}{l}\text { As in ERAI, but improving the representation of } \\
\text { mixed-phase clouds }\end{array}$ \\
\hline & WVP & $\begin{array}{l}\text { Prognostic information produced by forecasting } \\
\text { models }\end{array}$ & $\begin{array}{l}\text { As in ERAI, but assimilating several reprocessed } \\
\text { satellite datasets }\end{array}$ \\
\hline & Aerosol & $\begin{array}{l}\text { Climatological values from the Global Ozone } \\
\text { Chemistry Aerosol Radiation and } \\
\text { Transport model }\end{array}$ & $\begin{array}{l}\text { As in ERAI, but adding stratospheric sulfate } \\
\text { aerosols from major volcanic eruptions }\end{array}$ \\
\hline
\end{tabular}

satellite-derived aerosol optical depth (Feng and Wang 2019). In addition, biases of water vapor pressure (WVP) simulations by reanalyses should not be ignored when considering the attribution of the $R_{s}$ trend biases (H. Wang et al. 2018; Yang et al. 2019; Zhu et al. 2019).

The latest atmospheric reanalysis product from the ECMWF, ERA5, is the successor to ERA-Interim. ERA5 represents a major upgrade following 10 years of model and data assimilation developments. In particular, $R_{s}$ in ERA5 is produced by the Rapid Radiative Transfer Model shortwave scheme $\left(\right.$ RRTM $\left._{\mathrm{SW}}\right)$ which incorporates the Monte Carlo Independent Column Approximation (McICA) to represent subgrid cloud structures and overlap (Morcrette et al. 2008; ECMWF 2016). Recent studies have indicated that ERA5 reduces the mean biases in $R_{s}$ estimates referenced to the ground-based observations in Europe and at high latitudes (Urraca et al. 2018b; Babar et al. 2019). Nevertheless, there have been few assessments of the performance of the $R_{s}$ trends in China so far, and little attention has been paid to quantifying contributions of associated factors to the $R_{s}$ trend biases.

This study provides a comprehensive assessment of the reanalyzed $R_{s}$, including the climatology, monthly variations, and long-term trends from ERA5 and ERA-Interim by comparing with SunDu-derived $R_{s}$ from 1979 to 2014 at approximately 2200 stations in China. More importantly, this study analyzes the biases in $R_{s}$ trends and further quantifies the contributions of main factors [total cloud cover (TCC) and WVP] to the biases in $R_{s}$ trends. The contribution of the $R_{s}$ trend biases from aerosols is not quantified here because the reanalysis only input the aerosol climatology and does not output the direct and indirect effects of aerosols. In all, the findings of this investigation may help to understand the sources of biases in $R_{s}$ simulations and further improve climate change simulations in reanalysis.

\section{Data and methods}

\section{a. Reanalysis products}

Table 1 shows a summary of ERA5 and ERA-Interim. ERA5 is the latest atmospheric reanalysis from ECMWF and effectively replaces its predecessor, ERA-Interim (Hersbach and Dee 2016). ERA5 covers the period from 1979 onward (and eventually from 1950) and boasts much higher spatial and temporal resolutions than ERA-Interim (Berrisford et al. 2009). The intensive development of the Integrated Forecasting System (IFS) and the improvements in the acquisition observations jointly advance the production of ERA5 (Hersbach and Dee 2016). For more information on the advancements of ERA5 over ERA-Interim, the reader can refer to Hersbach and Dee (2016).

ERA-Interim and ERA5 do not assimilate $R_{s}$, cloud cover, and aerosol estimates from conventional or satellite observations into their model systems (ECMWF 2016; Urraca et al. 2018b). ERA-Interim uses a six-band shortwave parameterization model for $R_{s}$ and ERA5 uses the RRTM $\mathrm{Sw}$. For the simulation of clouds, they both use a prognostic scheme based on an equation of the sources and sinks of cloud areas (Berrisford et al. 2009). However, ERA5 improves the representation of mixed-phase clouds (Forbes and Ahlgrimm 2014). Climatological aerosol information from the Global Ozone Chemistry Aerosol Radiation and Transport (GOCART) model is used in both ERA-Interim and ERA5, but the latter includes stratospheric sulfate aerosols from major volcanic eruptions (Hersbach et al. 2019). They both use prognostic information produced by forecasting models to represent integrated column water vapor (Dee et al. 2011b), but ERA5 assimilates several reprocessed satellite datasets. The $R_{s}$, TCC, and WVP from ERA5 and ERA-Interim were converted into $1^{\circ} \times 1^{\circ}$ grids based on the bilinear interpolation method for the subsequent analysis in this study.

\section{b. Ground-based observations}

The homogeneous dataset from Zhou et al. (2018) was used in this study, including SunDu, TCC, WVP, air temperature, relative humidity, and surface pressure at approximately 2400 meteorological stations. These raw data are from the China Meteorological Administration (CMA; http://data.cma.cn/en) and eliminate the abrupt changes caused by artificial influences in the historical records using the RHtestsV4 software package (Wang et al. 2010). Approximately 2200 stations (Fig. 1) were 


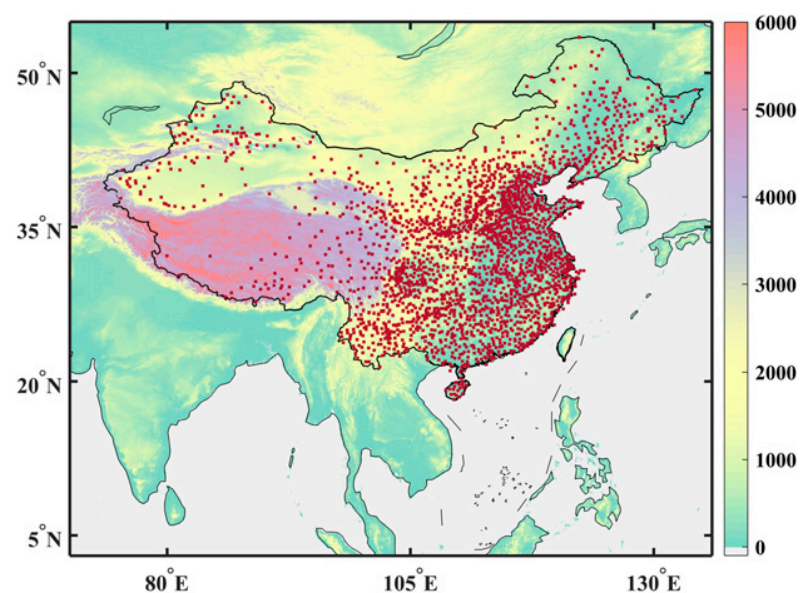

FIG. 1. Spatial distribution of approximately 2200 stations (red dots) throughout China. The color bar illustrates elevation (unit: $\mathrm{m}$ ).

selected based on series continuity and data length that require at least $80 \%$ of records for all the time scales, that is, $\geq 24$ days month ${ }^{-1}, \geq 10$ months $\mathrm{yr}^{-1}$, and $\geq 30$ years during the period of 1979-2014.

Frequent replacements of instruments measuring $R_{s}$ with a total of $\sim 100$ stations in China occurred during the period of 1990-93 to address previous instrument aging, but this caused abrupt breakpoints in time series during this period (Shi et al. 2008; Wang 2014). However, SunDu-derived $R_{s}$ has a good spatial coverage and long-term time series, and rarely suffers from the observation issues mentioned above. SunDu-derived $R_{s}$ has an advantage in depicting $R_{s}$ variability on monthly, annual, and decadal time scales (Yang et al. 2006; Tang et al. 2011; Wang et al. 2015; He et al. 2018), and it has been used as reference data to assess the performance of $R_{s}$ from the reanalyses (Zhou et al. 2018; Feng and Wang 2019).

In this study, SunDu-derived $R_{s}$ data were obtained from the dataset calculated by He et al. (2018), with a bias of $2.19 \mathrm{~W} \mathrm{~m}^{-2}$ $(1.36 \%)$ and a standard deviation of $19.32 \mathrm{~W} \mathrm{~m}^{-2}(12.02 \%)$ compared to monthly observed $R_{s}$. The method to derive $R_{s}$ is based on formulas (1) and (2) of the revised ÅngströmPrescott equations (see Yang et al. 2006):

$$
\begin{aligned}
& \frac{R_{s}}{R_{c}}=a_{0}+a_{1} \times\left(\frac{n}{N}\right)+a_{2} \times\left(\frac{n}{N}\right)^{2}, \\
& R_{c}=\int\left(\tau_{c_{-} \text {dir }}+\tau_{c \_ \text {dif }}\right) \times I_{0} d t,
\end{aligned}
$$

where $a_{0}, a_{1}$, and $a_{2}$ represent the regression coefficients of sunshine duration against the observed $R_{s}$ values in (1); $n$ and $N$ are the actual sunshine duration and the theoretical value of the sunshine duration, respectively; $I_{0}$ is the solar irradiance at the top of the atmosphere; $R_{c}$ is the surface solar radiation under clear skies based on local geographical and meteorological conditions and calculated by $(2)$; and $\tau_{c \_ \text {dir }}$ and $\tau_{c_{-} \text {dif }}$ denote the direct radiation transmittance and the diffuse radiation transmittance under clear skies, respectively. They were calculated by using a broad radiative transfer model developed by Yang et al. (2001), based on meteorological data (including air temperature, surface pressure, and relative humidity) from the CMA stations, turbidity coefficient calculated by Hess et al. (1998), and ozone thickness from the satellite products provided by National Aeronautics and Space Administration/Goddard Space Flight Center Ozone Processing Team.

It is worth noting that the number of meteorological stations of TCC over China decreased from around 2400 to 800 in 2014. Therefore, we used data from nearby stations whose correlation coefficient is more than 0.7 with the anomaly TCC of the candidate station to estimate its cloud cover data in 2014 based on the weighted average method (Yang et al. 2019).

\section{c. Method}

For consistency with reanalysis products, all the observations were integrated on the $1^{\circ} \times 1^{\circ}$ grids, which were averaged as national means with the area of each grid cell as weight. Some grids without meteorological stations are set to missing data, such as the Takla Makan Desert and Tibetan Plateau.

To evaluate the performance of both reanalysis products, we calculated the mean bias and the standard deviation of the biases between reanalysis products and observations. The mean bias was calculated by the monthly data between reanalysis products and observations, including the national mean bias and multiyear average bias. The standard deviation of the biases generally represents a measure of the variation in the biases or their dispersion (Bland and Altman 1996). To assess the effect of TCC and WVP biases from the reanalyses on $R_{S}$ biases, we selected months with highly accurate WVP (or TCC) and lowly accurate TCC (or WVP) estimates (i.e., high accuracy denotes that the relative error is less than $5 \%$ and low accuracy denotes that the relative error is more than $5 \%$ ) to calculate the multiyear average biases of $R_{s}$ and TCC (or WVP) from 1979 to 2014.

To exclude the effect of cloud cover on $R_{s}$ variation, we calculated the clear-sky index $\left(K_{c}=R_{s} / R_{c}\right)$ (Smith et al. 2017; Babar et al. 2019) and selected days with $K_{\mathrm{c}}$ greater than 0.8 to estimate the monthly $R_{s}$ from the ground-based observations, ERA-Interim, and ERA5 as solar radiation under the clear-sky condition. Note that $K_{c}$ accounts for atmospheric attenuation due to clouds and provides more information on the impacts of clouds on solar radiation than cloud cover values alone (Smith et al. 2017) and therefore depicts the possibilities of an obscured sun (Muneer and Gul 2000).

The trends of these quantities were calculated using the least squares method based on monthly $R_{s}$, TCC, and WVP anomalies relative to the reference period of 1981-2010:

$$
\begin{gathered}
X=k t+c+\varepsilon, \\
\Delta X=\Delta k t+c+\varepsilon,
\end{gathered}
$$

where $X$ represents monthly $R_{s}$, TCC, or WVP anomalies; $\Delta X$ denotes the biases of $R_{s}$, TCC, or WVP between the reanalysis products and observations; $k$ denotes the trend for $R_{s}$, TCC, or WVP; $\Delta k$ denotes the trend biases of $R_{s}$, TCC, or WVP; $t$ is the year; and $c$ and $\varepsilon$ represent the constant (or the intercept) and residual, respectively. 

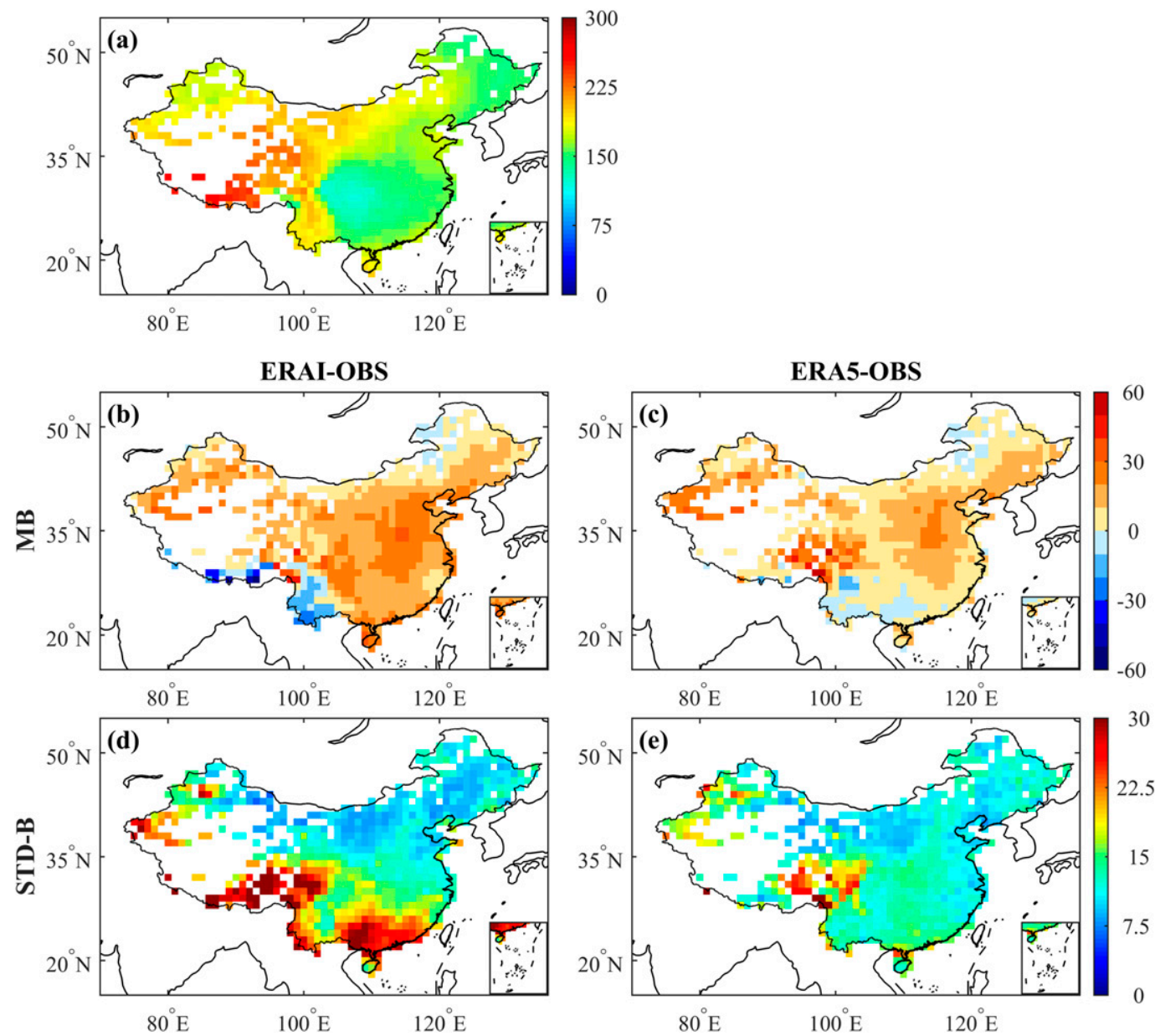

FIG. 2. (a) Multiyear average of monthly surface incident solar radiation $\left(R_{s}\right.$, unit: $\left.\mathrm{W} \mathrm{m}^{-2}\right)$ from the ground-based observations (OBS). (b),(c) Multiyear mean biases (MB) in $R_{s}$ of ERA-Interim and ERA5 referenced to OBS. (d),(e) Standard deviation of these biases (STD-B).

To quantify the contributions of TCC and WVP to the $R_{s}$ trend biases, a polynomial regression model was used in this study:

$$
\begin{aligned}
\Delta X_{s_{R}} & =\beta_{\mathrm{TCC}} \Delta X_{\mathrm{TCC}}+\beta_{\mathrm{WVP}} \Delta X_{\mathrm{WVP}}+c+\varepsilon, \\
\mathrm{Ct}_{\mathrm{TCC}} & =\beta_{\mathrm{TCC}} \times \Delta k_{\mathrm{TCC}}, \\
\mathrm{Ct}_{\mathrm{WVP}} & =\beta_{\mathrm{WVP}} \times \Delta k_{\mathrm{WVP}},
\end{aligned}
$$

where $\Delta X_{R_{s}}, \Delta X_{\mathrm{TCC}}$, and $\Delta X_{\mathrm{WVP}}$ denote the biases in the anomaly of $R_{s}$, TCC, and WVP between the reanalysis products and observations, respectively; $\Delta k_{\mathrm{TCC}}\left(\Delta k_{\mathrm{WVP}}\right)$ denotes the corresponding trend biases for TCC (WVP); $\beta_{\mathrm{TCC}}\left(\beta_{\mathrm{WVP}}\right)$ is the partial regression coefficient for TCC (WVP), which represents the sensitivity of the bias of $R_{s}$ to TCC (WVP); $c$ and $\varepsilon$ represent the constant and residual, respectively; and $\mathrm{Ct}_{\mathrm{TCC}}$ ( $\left.\mathrm{Ct}_{\mathrm{WVP}}\right)$ represents the contribution of the trend biases of $R_{s}$ from TCC (WVP).

\section{Results}

\section{a. Comparison of multiyear average $R_{s}$ from reanalysis products}

Figure 2 shows the multiyear average $R_{s}$ values and their biases between ERA-Interim or ERA5 and the ground-based observations during the period of 1979-2014. Based on the $R_{s}$ estimates from the ground-based observations (Fig. 2a), the spatial distribution of the multiyear average $R_{s}$ depicts an increase from the southeast to the northwest; the values are higher on the Tibetan Plateau with a range of $200-300 \mathrm{~W} \mathrm{~m}^{-2}$ due to thin air from its high altitude, low aerosol loading, and cloud cover (Yang et al. 2012; You et al. 2013). Both ERA5 and ERA-Interim underestimate the $R_{s}$ values in Southwest China $\left(20^{\circ}-27^{\circ} \mathrm{N}, 95^{\circ}-100^{\circ} \mathrm{E}\right)$ but overestimate them in the North China Plain $\left(32^{\circ}-40^{\circ} \mathrm{N}, 114^{\circ}-121^{\circ} \mathrm{E}\right)$, Northwest China $\left(35^{\circ}-\right.$ $\left.50^{\circ} \mathrm{N}, 70^{\circ}-90^{\circ} \mathrm{E}\right)$, and Southeast China $\left(20^{\circ}-32^{\circ} \mathrm{N}, 105^{\circ}-125^{\circ} \mathrm{E}\right)$. However, ERA5 performs better at capturing the multiyear average $R_{s}$ than ERA-Interim with lower mean biases and 

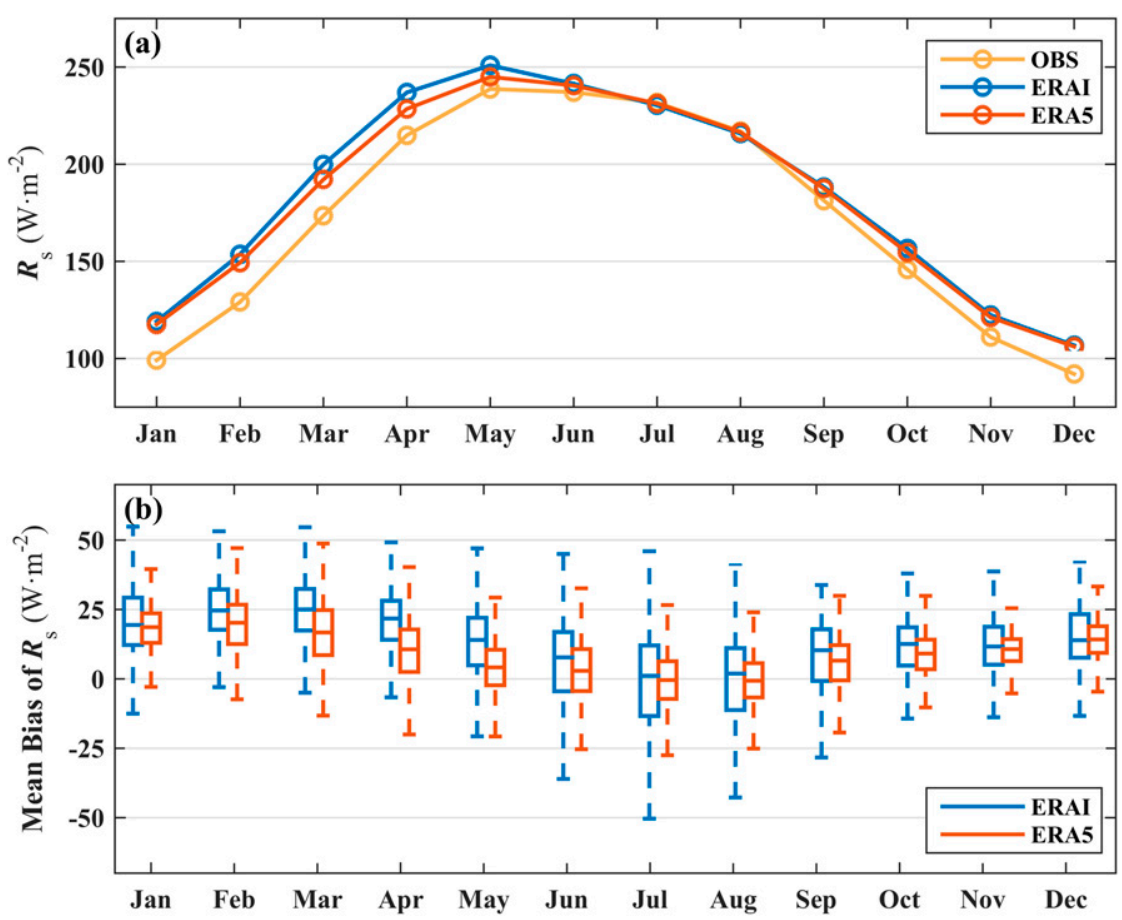

FIG. 3. (a) Seasonal cycle of surface incident solar radiation $\left(R_{s}\right.$, unit: $\left.\mathrm{W} \mathrm{m}^{-2}\right)$ in China during the period of 1979-2014 from ground-based observations (OBS; yellow), ERA-Interim (blue), and ERA5 (red). (b) Seasonal cycle of mean biases between the reanalyses and observations.

smaller dispersion degree of $R_{s}$ monthly biases, especially in South China $\left(20^{\circ}-28^{\circ} \mathrm{N}, 100^{\circ}-120^{\circ} \mathrm{E}\right)$ and Southwest China (Fig. 2; see also Fig. S1 in the online supplemental material). ERA5 also shows a higher accuracy with the national mean bias $(\mathrm{MB})$ of $10.07 \mathrm{~W} \mathrm{~m}^{-2}$ and the standard deviation of the biases (STD-B) of $9.11 \mathrm{~W} \mathrm{~m}^{-2}$ than ERA-Interim $(\mathrm{MB}=$ $15.88 \mathrm{~W} \mathrm{~m}^{-2}$ and STD-B $=10.84 \mathrm{~W} \mathrm{~m}^{-2}$ ).

Figure 3 illustrates the seasonal cycle of national mean $R_{s}$ in the reanalysis products and the ground-based observations from 1979 to 2014 . The monthly $R_{s}$ values of the reanalyses are obviously overestimated except in summer. The national mean biases are lower in summer (i.e., June to August), which is due to their spatial differences leading to the offset of positive and negative biases (Figs. 3 and 4). ERA5 has better performance for $R_{s}$ at seasonal scales than ERA-Interim, with lower mean bias and smaller dispersion (Figs. 3 and 4).

In the clear-sky condition, ERA5 overestimates the multiyear average of $R_{s}$ values in the North China Plain and Northwest China but underestimates the $R_{s}$ values in South China and Northeast China (Fig. 5c). This also happens to ERA-Interim, but the magnitude of $R_{s}$ biases from ERAInterim is higher than that from ERA5 (Figs. 5d,g).

\section{b. Comparison of multiyear average TCC and WVP from reanalysis products}

The biases of the multiyear average TCC have a spatial distribution opposite to the $R_{s}$ biases (Figs. 2 and 6). The overestimated TCC values occur in Southwest China and Northeast China, which directly corresponds to the underestimated $R_{s}$ values. This shows that they roughly explain some differences in $R_{s}$ from the reanalyses; that is, the overestimations of TCC could cause the underestimations of $R_{s}$ and vice versa. ERA5 greatly improves the performance of TCC simulation with smaller magnitude of the biases (Figs. 6 and 7; see also Fig. S1) to alleviate the $R_{s}$ biases, probably because of the high vertical and horizontal resolutions and the improved cloud scheme. For example, over eastern China, a smaller magnitude of positive $R_{s}$ biases from ERA5 may be due to the improvement of TCC estimates (see Figs. S1a and S1b). In summer, ERA5 slightly overestimates TCC values in South China (Fig. 7), which might explain some underestimation of $R_{s}$ from ERA5. ERA-Interim displays a large negative bias of TCC with a small dispersion of deviation in summer but a low bias with a large dispersion in winter, whose performance of TCC simulation is generally weaker than ERA5.

ERA5 does not seem to significantly improve the performance of WVP's multiyear average in the all-sky and clear-sky conditions (Figs. 5 and 6; see also Fig. S1). ERA-Interim and ERA5 both most severely underestimate WVP (Fig. 6) in the all-sky condition, especially in summer with larger negative biases and their dispersion, and they have no obvious spatial differences at seasonal time scales (not shown). Together with the underestimations of TCC between the reanalyses and observations, the underestimations of WVP results in $R_{s}$ biases are positive for most of China due to their missing extinction effect on solar radiation (Fig. 2). In the clear-sky condition, WVP biases from ERA-Interim and ERA5 in South China show higher magnitude than those in the all-sky condition. 


\section{ERA-Interim}

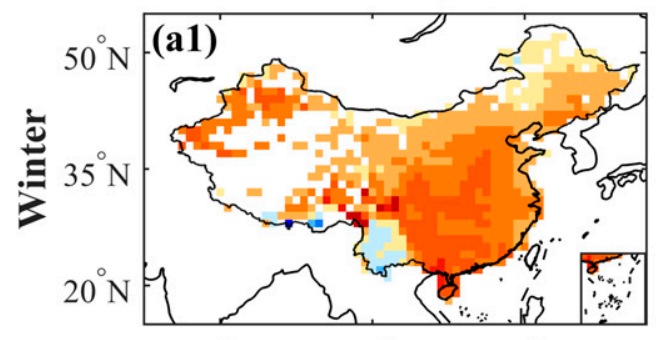

$80^{\circ} \mathrm{E} \quad 100^{\circ} \mathrm{E} \quad 120^{\circ} \mathrm{E}$

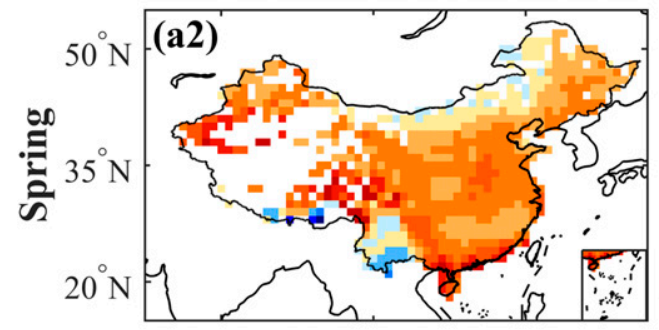

$80^{\circ} \mathrm{E} \quad 100^{\circ} \mathrm{E} \quad 120^{\circ} \mathrm{E}$

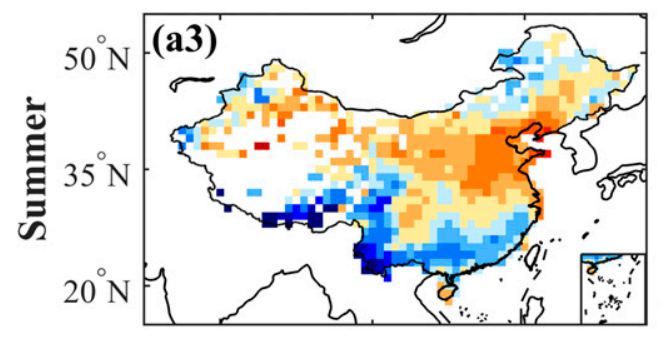

$80^{\circ} \mathrm{E} \quad 100^{\circ} \mathrm{E} \quad 120^{\circ} \mathrm{E}$

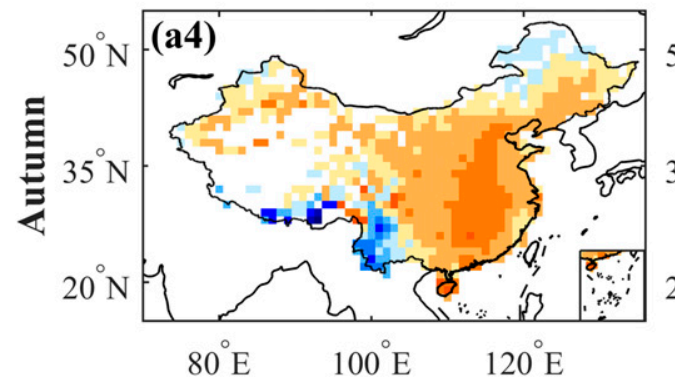

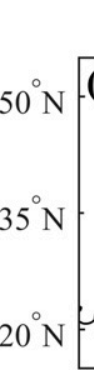

\section{ERA5}

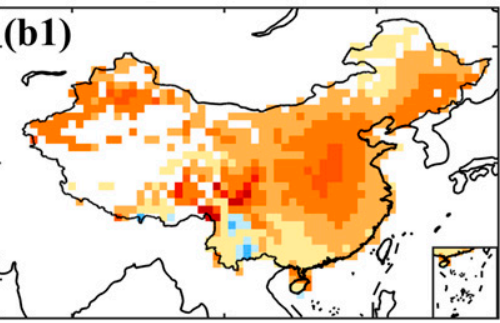

$80^{\circ} \mathrm{E} \quad 100^{\circ} \mathrm{E} \quad 120^{\circ} \mathrm{E}$

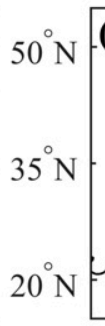

\section{(b2)}

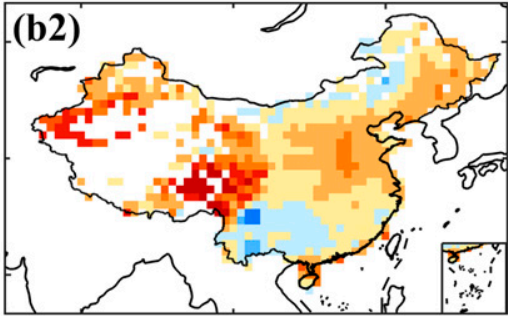

$80^{\circ} \mathrm{E} \quad 100^{\circ} \mathrm{E} \quad 120^{\circ} \mathrm{E}$

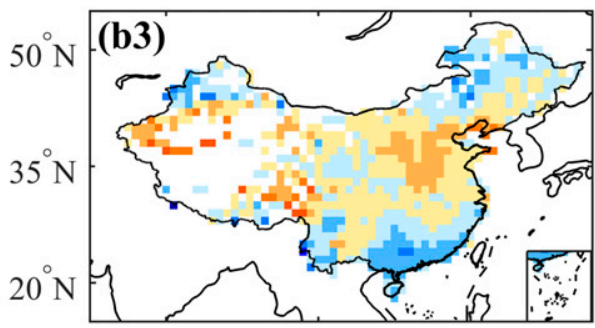

$80^{\circ} \mathrm{E} \quad 100^{\circ} \mathrm{E} \quad 120^{\circ} \mathrm{E}$

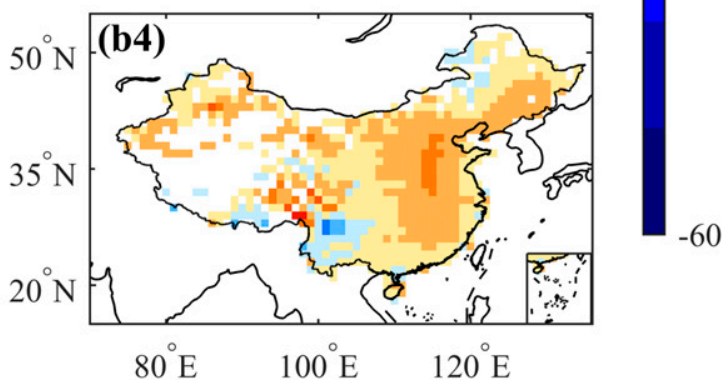

FIG. 4. Spatial distribution of the multiyear average differences in monthly surface incident solar radiation $\left(R_{s}\right.$; unit: $\mathrm{W} \mathrm{m}^{-2}$ ) between the reanalyses and ground-based observations in winter (December-February), spring (March-May), summer (June-August), and autumn (September-November).

While ensuring highly accurate TCC (the relative error is less than $5 \%$ between monthly data of the reanalyses and observations) and somewhat accurate WVP estimates (the relative error is more than $5 \%$ ), the multiyear average $R_{s}$ is overestimated in China except in South China and the multiyear average WVP is underestimated over China (the first column of Fig. 8). For each reanalysis, the comparison of the multiyear average biases in $R_{s}$ with those in TCC or WVP (e.g., Fig. 8a vs Fig. 8d) is not related to the seasonality because they are averaged in the same months for each case. For the case comparison between ERA-Interim and ERA5, it may be related to seasonality. However, the seasonality of differences in the $R_{s}$ biases between ERA-Interim and ERA5 is much smaller than that of the $R_{s}$ biases themselves in each reanalysis (Fig. 3b). Compared with ERA-Interim, ERA5 has smaller magnitude of biases under the conditions of highly accurate TCC and less accurate WVP (the first column of Fig. 8) and highly accurate WVP and less accurate TCC (second column of Fig. 8), which shows that the $R_{s}$ biases are both diminished due to the ERA5 improvements of TCC or WVP. Simultaneously, we also found that the improvement of TCC in ERA5 seems to be obvious with higher numbers of months meeting the case of 

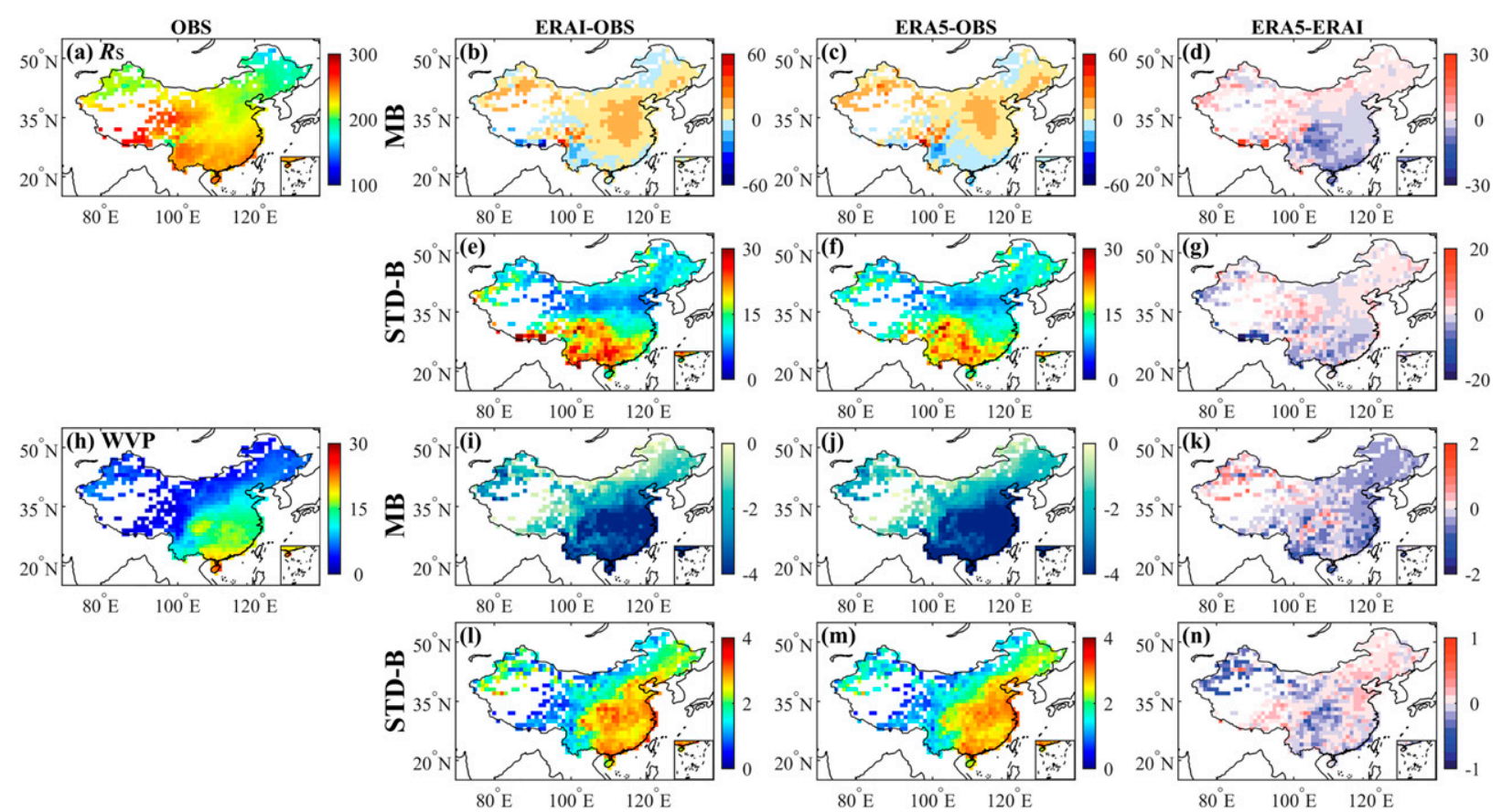

FIG. 5. Spatial difference in the multiyear average of monthly (a)- $(\mathrm{g})$ surface incident solar radiation $\left(R_{s} ;\right.$ unit: $\left.\mathrm{W} \mathrm{m}^{-2}\right)$ and $(\mathrm{h})-(\mathrm{n})$ water vapor pressure (WVP; unit: hPa) between the reanalyses (ERAI or ERA5) and ground-based observations (OBS) in the clear-sky condition during the period of 1979-2014. (left) The multiyear average $R_{s}$ in (a) and WVP in (h) from ground-based observations. MB = mean bias; STD-B = standard deviation of the biases.

highly accurate TCC estimates (Fig. S2). Under the highly accurate estimates of TCC and WVP, the North China Plain still displays larger $R_{s}$ biases with lower numbers of months meeting this case (Fig. 8; see also Fig. S2). This might be attributed to the much larger aerosol loading in this region (Kalnay and Cai 2003), which has increased dramatically in the past (Li et al. 2016; X. Wang et al. 2018), while aerosol loading cannot seem to explain the negative $R_{s}$ bias in South China.

\section{c. Comparison of trends in $R_{s}$ from reanalysis products}

There is a higher correlation of $0.83(p<0.05)$ between monthly $R_{s}$ anomalies from ground-based observations and ERA5 than between monthly $R_{s}$ anomalies from ground-based observations and ERA-Interim $(R=0.78, p<0.05)$ (Fig. 9). Figure 10 depicts the national mean time series of anomaly $R_{s}$, TCC, and WVP over China from 1979 to 2014. The observed $R_{s}$ shows a continuous decline until $1993\left(-3.31 \mathrm{~W} \mathrm{~m}^{-2}\right.$ decade $^{-1}$; $p<0.05)$ and then stabilizes with a nonsignificant trend of $0.30 \mathrm{~W} \mathrm{~m}^{-2}$ decade $^{-1}$ from 1994 to 2014 (Table 2 and Fig. 10a). In the clear-sky condition, although a decreasing trend $\left(-0.97 \mathrm{~W} \mathrm{~m}^{-2}\right.$ decade $\left.^{-1} ; p<0.05\right)$ still occurs in China from 1979 to 1993 , its magnitude is lower than that in the all-sky condition; after that, the change of $R_{s}$ is significantly reversed with an increase trend of $0.90 \mathrm{~W} \mathrm{~m}^{-2}$ decade $^{-1}(p<0.05)$ (Table 2). Due to using the radiative transfer model and considering TCC and WVP simulations, the reanalyses both show $R_{S}$ trend discrepancies over the different time periods 1979-93, 1993-2014, and 1979-2014.
From 1979 to 1993, ERA-Interim $\left(-1.99 \mathrm{~W} \mathrm{~m}^{-2}\right.$ decade $^{-1}$; $p<0.05)$ and ERA5 $\left(-2.42 \mathrm{~W} \mathrm{~m}^{-2}\right.$ decade $\left.^{-1} ; p<0.05\right)$ both reproduce the dimming in $R_{s}$ (Table 2 and Fig. 10a). Simultaneously, the national mean TCC trends from 1979 to 1993 show no obvious differences in the reanalyses and observations (Fig. 10b). However, the increased WVP trend is underestimated by ERA-Interim $\left(0.07 \mathrm{hPa}\right.$ decade $^{-1} ; p>$ $0.1)$ and ERA5 $\left(0.08 \mathrm{hPa}\right.$ decade $\left.{ }^{-1} ; p>0.1\right)$ comparing with observations $\left(0.22 \mathrm{hPa}\right.$ decade $\left.^{-1} ; p<0.05\right)$, respectively. The underestimation of positive WVP trends from the reanalyses may contribute to their magnitude of $R_{s}$ trends lower than negatively observed $R_{s}$ trend (Table 2).

During the period of 1994-2014, the reanalyses simulate significantly increased $R_{s}$ trends with $2.26 \mathrm{~W} \mathrm{~m}^{-2}$ decade $^{-1}$ $(p<0.05)$ for ERA-Interim and $1.49 \mathrm{~W} \mathrm{~m}^{-2}$ decade $^{-1}(p<0.05)$ for ERA5. For TCC trends, ERA-Interim $\left(-0.01\right.$ decade $^{-1}$; $p<0.05)$ and ERA5 $\left(-0.01\right.$ decade $\left.^{-1} ; p<0.10\right)$ both tend to change in the reverse direction with the observed TCC (0.02 decade de $\left.^{-1} ; p<0.05\right)$, to probably lead to their differences in $R_{s}$. The national mean WVP over China from the dataset (Zhou et al. 2018) decreases significantly since 1994 $\left(-0.18 \mathrm{hPa}\right.$ decade $\left.{ }^{-1} ; p<0.05\right)$, while ERA-Interim and ERA5 underestimate its decreasing trend with $-0.11 \mathrm{hPa}$ decade $^{-1}$ $(p<0.10)$ and $-0.13 \mathrm{hPa}$ decade ${ }^{-1}(p<0.05)$, respectively. In the clear-sky condition, ERA-Interim and ERA5 both show a nonsignificant downtrend in $R_{s}$ from 1979 to 1993 , and a significant increase trend from 1994 to 2014. The magnitude of these two periods is lower that the observed values. 
TCC
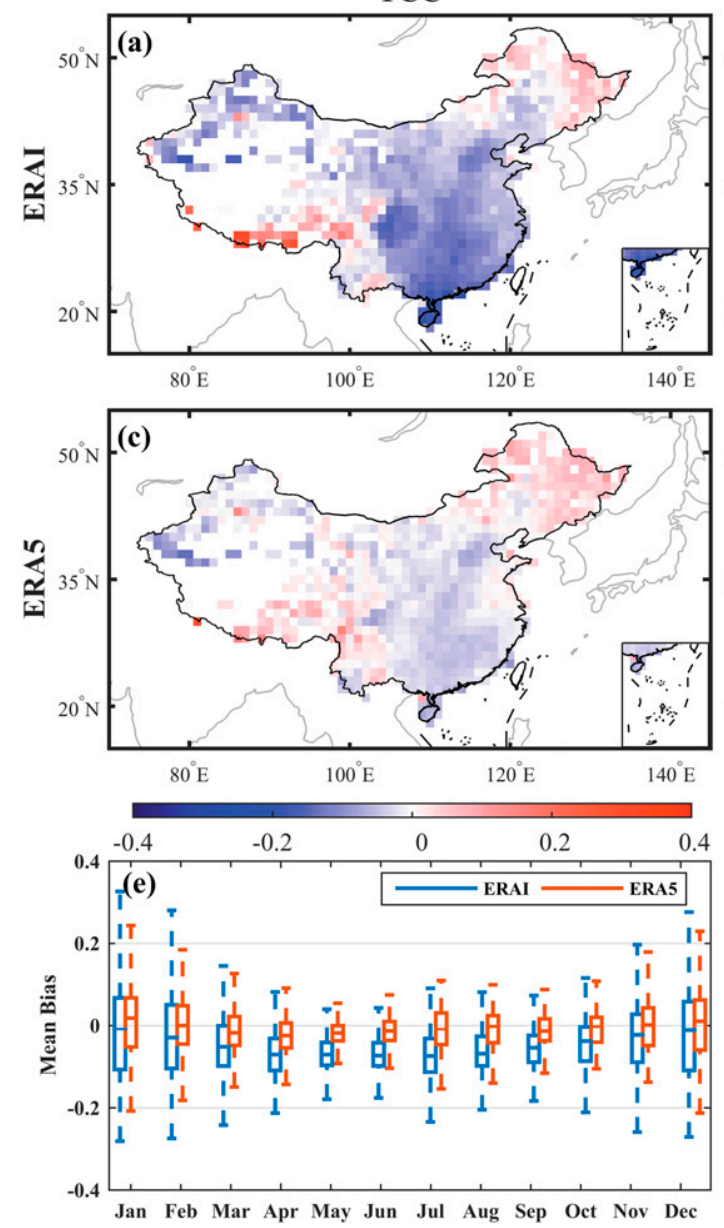
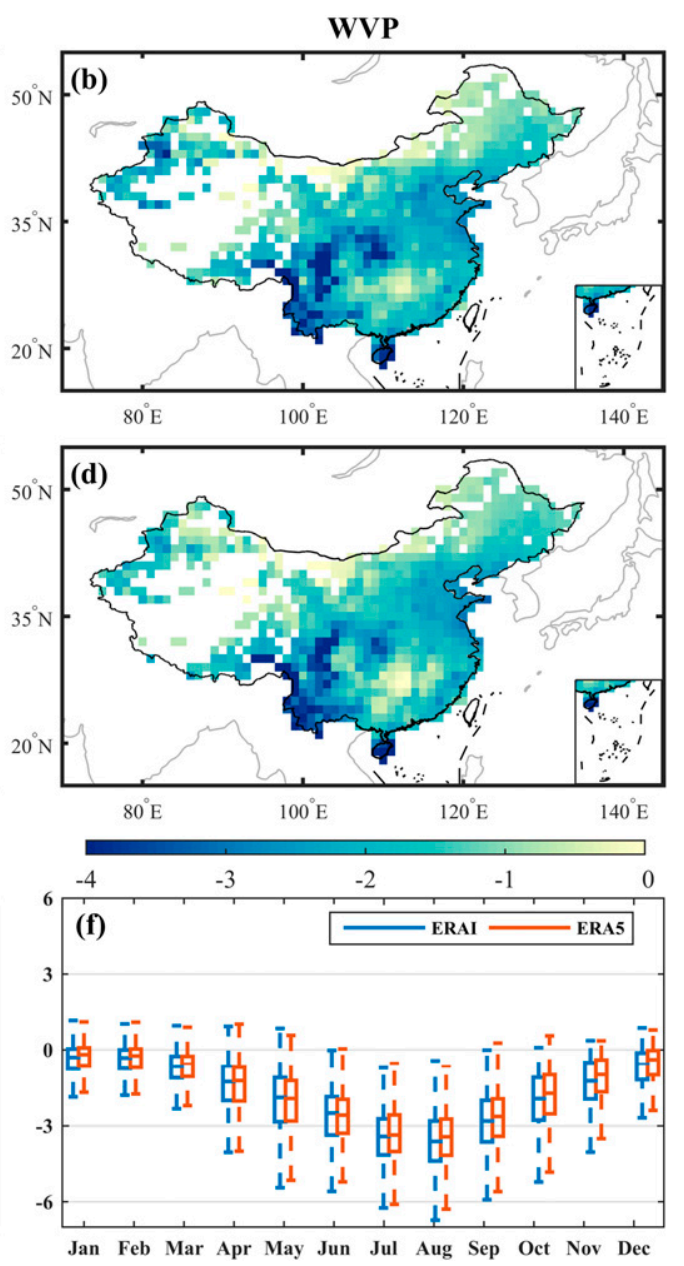

FIG. 6. (a)-(d) Spatial difference of the multiyear average of monthly total cloud cover (TCC; unit: 1) and water vapor pressure (WVP; unit: hPa) from ERA-Interim and ERA5 relative to the ground-based observations in China during the period of 1979-2014. (e),(f) Monthly bias of the national mean TCC and WVP from ERA-Interim (blue) and ERA5 (red).

From 1979 to 2014, the $R_{s}$ values from the ground-based observations display a national average trend of $-0.47 \mathrm{~W} \mathrm{~m}^{-2}$ decade $^{-1}$ $(p<0.10)$ (Table 2), with significant decreases in North China [Fig. 11a(1))] Correspondingly, the observed TCC trends have an opposite spatial distribution to $R_{s}$ in North China [Fig. 11a(2)], which affects some changes of $R_{s}$ trends. Like TCC, the WVP trends decrease in some parts of South China and increase elsewhere with a national average trend of $0.06 \mathrm{hPa} \mathrm{decade}^{-1}(p<0.10)$ in China [Fig. 11a(3)]. Unfortunately, ERA-Interim and ERA5 both show poor performance in simulating $R_{S}$ trends during the period of 1979-2014 with positive biases of $1.33 \pm 0.38 \mathrm{~W} \mathrm{~m}^{-2} \mathrm{decade}^{-1}(p<0.05)$ and $1.36 \pm 0.31 \mathrm{~W} \mathrm{~m}^{-2}$ decade $^{-1}(p<0.05)$, respectively (Fig. 11 and Table 2). Trend biases in TCC and WVP between the reanalyses and observations display reverse spatial distributions compared with $R_{s}$ trend biases (Fig. 11).

We further quantify the contributions of TCC and WVP from ERA-Interim and ERA5 to the national mean bias in the $R_{s}$ trend (Table 2). We found that the improvement of TCC simulation from ERA5 may result in smaller contribution of TCC biases to $R_{s}$ trend biases, and accordingly the contribution of WVP biases will be more prominent. The TCC (WVP) trend biases from ERA5 can explain 54\% (36\%) of the biases in the $R_{s}$ trend, and those from ERA-Interim explain 58\% (20\%) of the biases in the $R_{s}$ trend from 1979 to 2014 (Table 2). During the period of 1979 to 1993, the biases of $R_{s}$ trend from ERA-Interim and ERA5 are $1.31 \mathrm{~W} \mathrm{~m}^{-2}$ decade $^{-1}(p<0.05)$ and $0.89 \mathrm{~W} \mathrm{~m}^{-2} \operatorname{decade}^{-1}(p<$ $0.05)$, respectively, $59 \%$ and $71 \%$ of which can be explained by the WVP trend biases. However, during the period of 1994-2014, the effect of TCC trend biases on $R_{s}$ is more prominent (Table 2).

\section{$d$. Trends of $R_{s}$ from the spatially complete reanalysis products}

Figure 12 shows the spatial distributions of $R_{s}$ trend from the spatially complete reanalyses (ERA5 and ERA-Interim). From 1979 to $1993, R_{s}$ from ERA5 significantly decreases over China with a national mean trend of $-2.12 \mathrm{~W} \mathrm{~m}^{-2}$ decade $^{-1}(p<$ $0.05)$, and ERA-Interim displays smaller magnitude of decreasing 
ERA-Interim
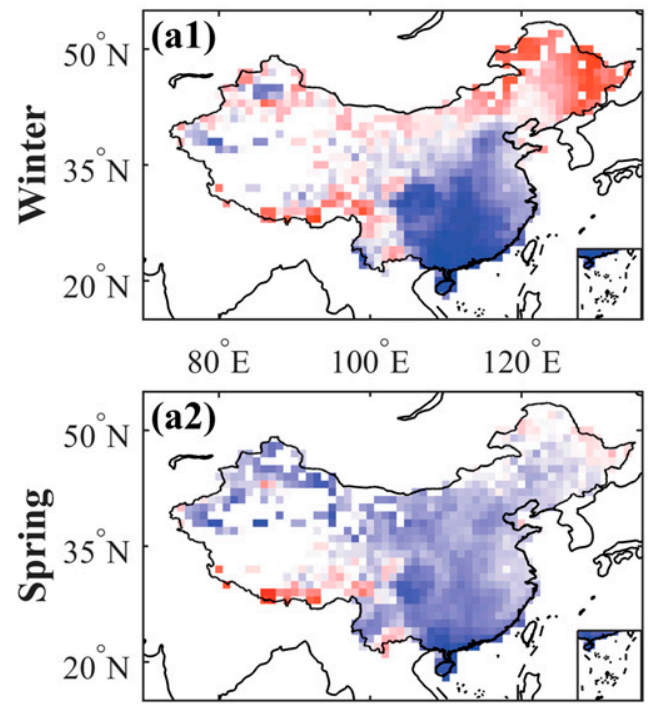

$80^{\circ} \mathrm{E} \quad 100^{\circ} \mathrm{E} \quad 120^{\circ} \mathrm{E}$

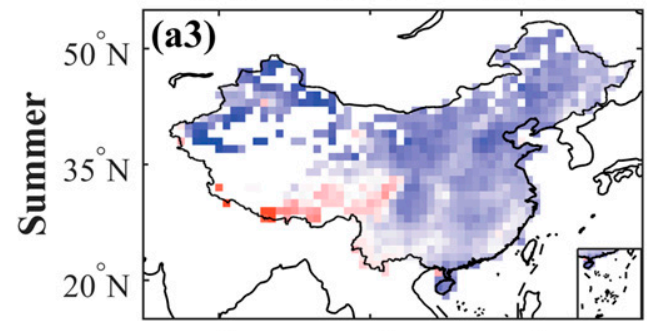

$80^{\circ} \mathrm{E} \quad 100^{\circ} \mathrm{E} \quad 120^{\circ} \mathrm{E}$

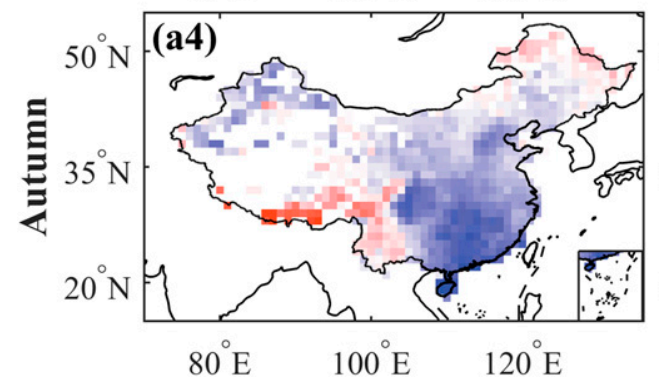

\section{ERA5}

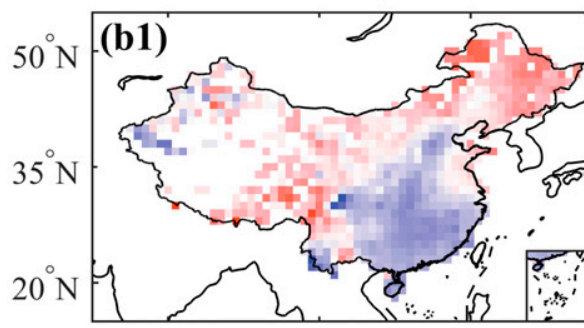

$80^{\circ} \mathrm{E} \quad 100^{\circ} \mathrm{E} \quad 120^{\circ} \mathrm{E}$
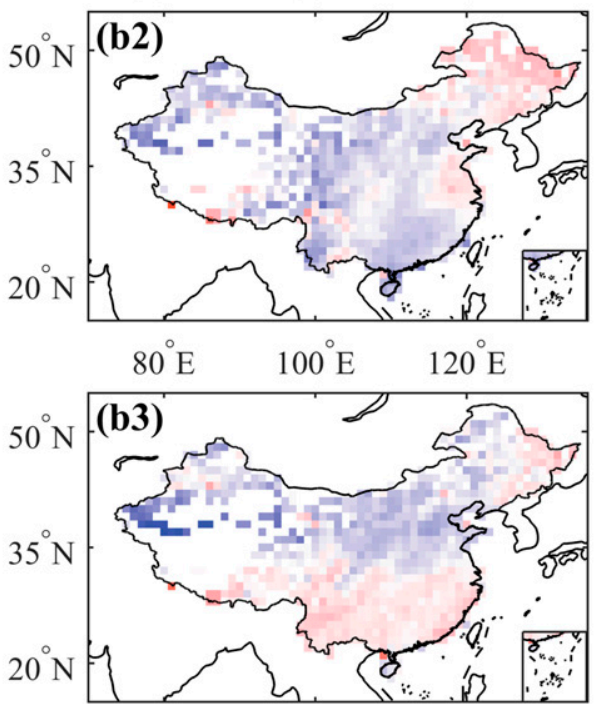

$80^{\circ} \mathrm{E} \quad 100^{\circ} \mathrm{E} \quad 120^{\circ} \mathrm{E}$

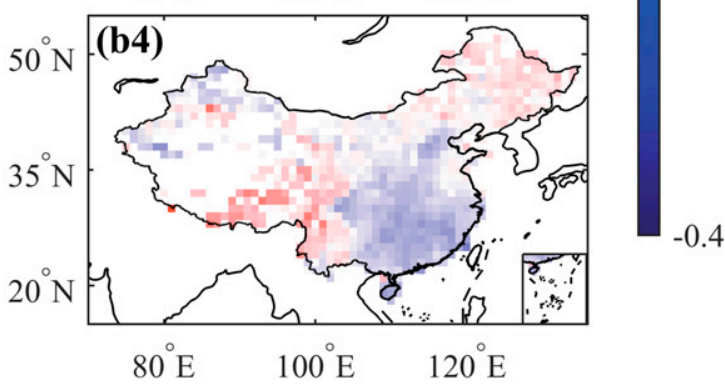

FIG. 7. Spatial difference of the multiyear average in monthly total cloud cover (TCC, unit: 1) between the reanalyses and ground-based observations in winter (December-February), spring (March-May), summer (JuneAugust), and autumn (September-November).

trends except in the south of South China $\left(16^{\circ}-28^{\circ} \mathrm{N}, 103^{\circ}-\right.$ $\left.115^{\circ} \mathrm{E}\right)$ with a national mean trend of $-1.68 \mathrm{~W} \mathrm{~m}^{-2}$ decade $^{-1}$ $(p<0.05)$ (Fig. 12 and Table 2). From 1994 to 2014, ERA5 and ERA-Interim both have a sharply increased $R_{s}$ trend in South China and a decreasing trend in parts of the Tibetan Plateau. The national mean $R_{s}$ trend from ERA5 $\left(1.19 \mathrm{~W} \mathrm{~m}^{-2}\right.$ decade $^{-1}$; $p<0.05)$ during this period is lower than that of ERA-Interim $\left(2.06 \mathrm{~W} \mathrm{~m}^{-2}\right.$ decade $\left.^{-1} ; p<0.05\right)$ (Table 2). From 1979 to 2014, there is no significant difference between $R_{s}$ trend from ERA5 and ERA-Interim in terms of the spatial patterns and national average (Fig. 12 and Table 2).

\section{Conclusions and discussion}

This study provides a quantitative examination of the ability of ERA-Interim and the latest reanalysis product (ERA5) to estimate $R_{s}$ over China from 1979 to 2014, and the evaluation includes climatology and trend considerations. We compared the $R_{s}$ estimates from ERA-Interim and ERA5 and quantified the contributions of TCC and WVP to the biases in the $R_{s}$ trends. Our results show that, ERA5 overestimates the multiyear average $R_{s}$ in most regions of China in the all-sky and clear-sky conditions, whereas the biases and their dispersion 


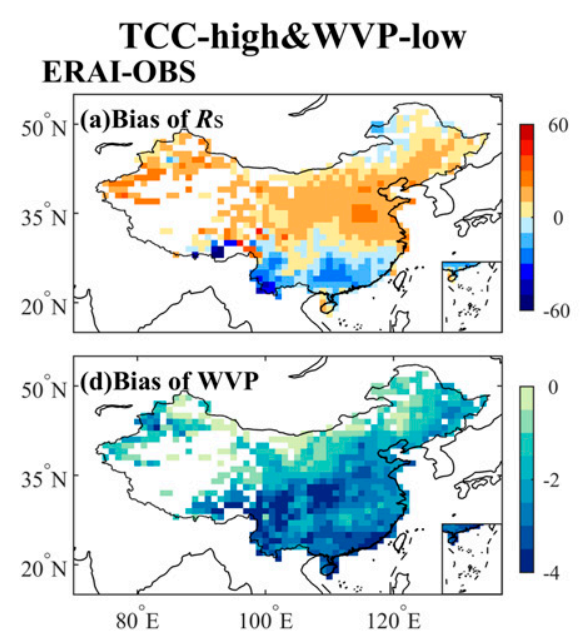

\section{WVP-high\&TCC-low}
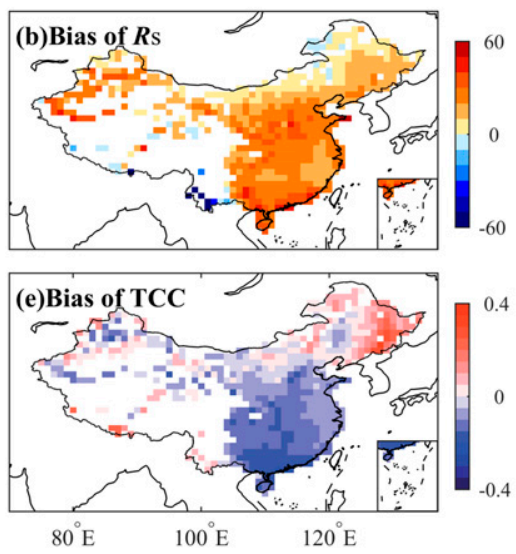

\section{ERA5-OBS}
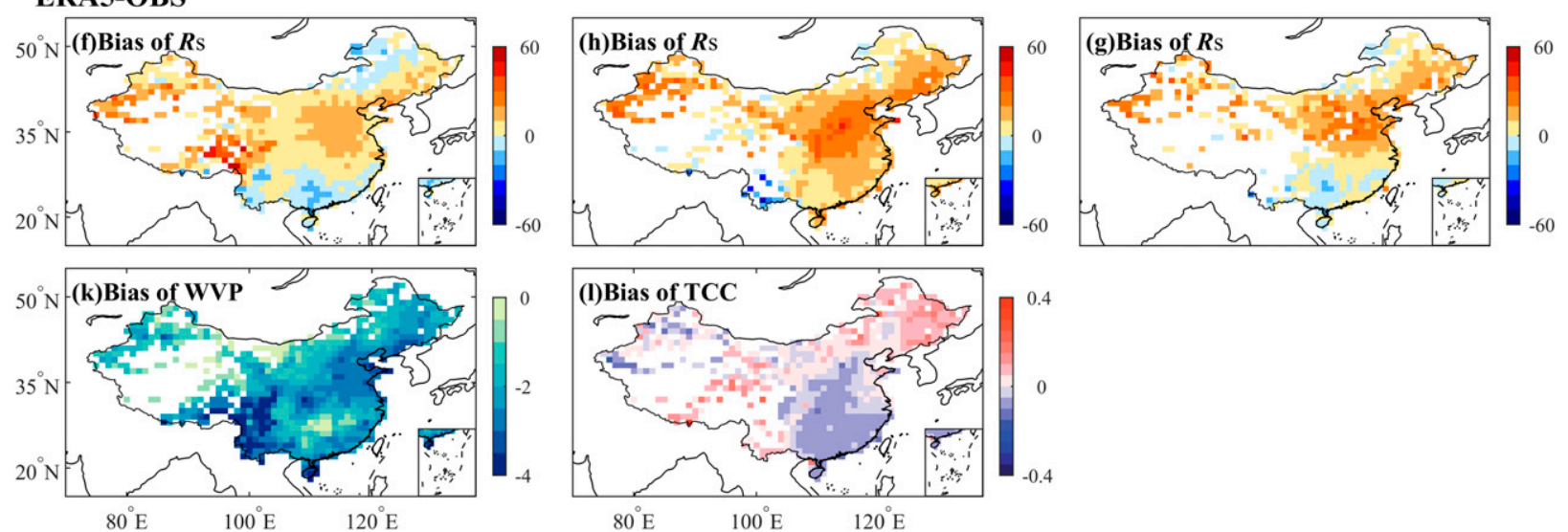

FIG. 8. Comparisons of the multiyear average in monthly surface incident solar radiation $\left(R_{s} ; \mathrm{unit} \mathrm{W} \mathrm{m}^{-2}\right)$, total cloud cover (TCC; unit: 1), and water vapor pressure (WVP; unit: hPa) between the reanalyses and ground-based observations in three cases, with (a),(d),(f),(k) highly accurate TCC and less accurate WVP estimates (TCC-high and WVP-low), (b),(e),(h),(l) highly accurate WVP and less accurate TCC estimates (WVP-high and TCC-low), and (c),(g) highly accurate TCC and WVP estimates (Both-high).

degree are reduced compared to those from ERA-Interim. In other studies, ERA5 also shows a moderate positive bias of $R_{s}$ in Europe, in Australia, and at high altitudes and has better performance compared with ERA-Interim, MERRA2, and other reanalyses (Huang et al. 2018; Urraca et al. 2018b, a; Babar et al. 2019).

Unfortunately, neither ERA-Interim nor ERA5 can reproduce the variations in the $R_{s}$ trends from 1979 to 2014, with opposite signs of trend using the SunDu-derived $R_{s}$ based on the ground-based observations as a reference. The observed $R_{s}$ values decrease $\left(-0.47 \mathrm{~W} \mathrm{~m}^{-2}\right.$ decade $\left.^{-1} ; p<0.10\right)$ but those from ERA-Interim and ERA5 increase by $0.86 \mathrm{~W} \mathrm{~m}^{-2}$ decade $^{-1}$ $(p<0.05)$ and $0.89 \mathrm{~W} \mathrm{~m}^{-2}$ decade $^{-1}(p<0.05)$, respectively. In the period of 1979-93, the observed $R_{s}$ has a significant decreasing trend of $-3.31 \mathrm{~W} \mathrm{~m}^{-2}$ decade $^{-1}$ and the reanalyses both reproduce the dimming phenomenon. Their degree of dimming in the clear-sky condition is weaker than that in the all-sky condition. Since 1994, ERA-Interim and ERA5 have reversed with significant increase in $R_{s}$ but the observations have leveled off in the all-sky condition. In the clear-sky condition, the observed $R_{s}$ shows more obvious brightening from 1994 to 2014, but the brightening of ERA-Interim and ERA5 is weaker.

Compared to ERA-Interim, we found that ERA5 is superior in simulating the multiyear average TCC, while the WVP from ERA5 has not improved much. Based on the RRTM SW $_{2}$ scheme incorporating the McICA approach and the revised cloud optical properties, ERA5 also improves the accuracy of the $R_{s}$ estimates. However, due to the limited horizontal and vertical resolutions and the uncertainties in the parameterization of physical processes near the cloud top, the cloud-top reflectance error still exists to interfere with the $R_{s}$ estimates from ERA5 (Forbes and Ahlgrimm 2014). In addition, TCC trends from reanalyses are significantly underestimated, partly because the impacts of varying aerosols on clouds (i.e., aerosol indirect radiative effects) are not included in reanalyses through increasing cloud droplet number concentration and reducing cloud droplet effective radius (Haywood and Boucher 2000; Zhao et al. 2019). These underestimated TCC trends can lead to larger $R_{s}$ trend biases. 

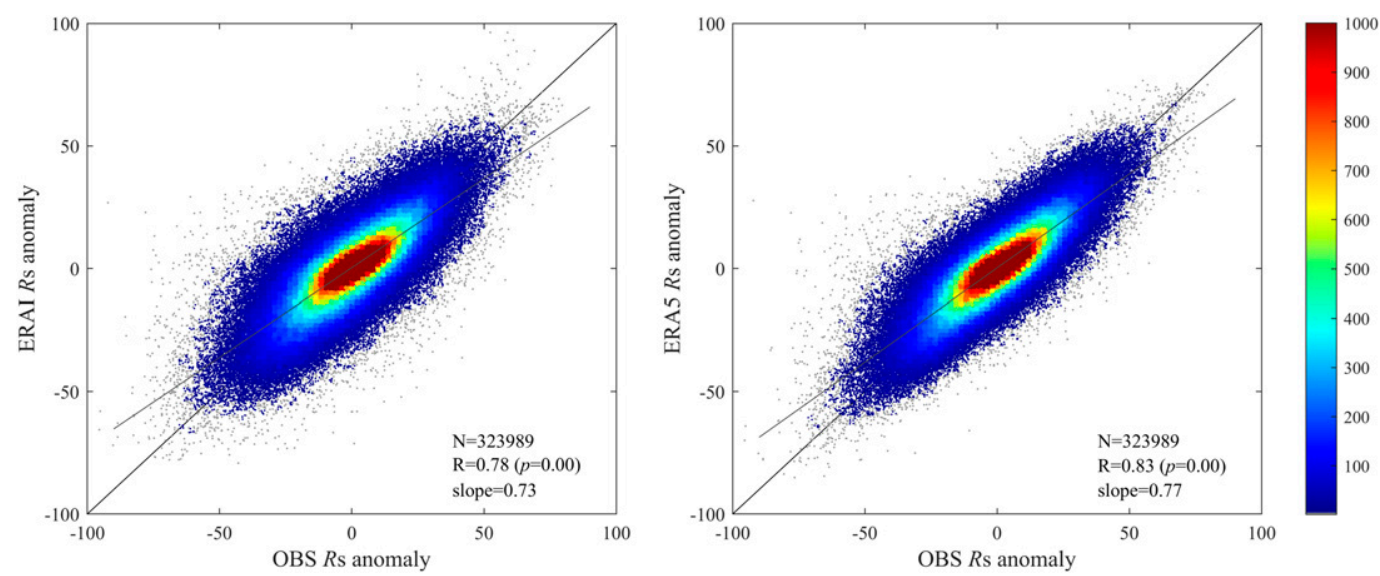

FIG. 9. Comparisons of the monthly anomaly surface incident solar radiation $\left(R_{s} ;\right.$ unit: $\left.\mathrm{W} \mathrm{m}^{-2}\right)$ from (left) observations and ERA-Interim (right) and from observations and ERA5. The color bar denotes the scatter density. In the lower-right corner of each plot $N$ denotes the numbers of monthly records and $R$ denotes the correlation coefficient.

We further found that during the period of 1979-2014, the biases in the TCC trend from ERA-Interim and ERA5 can explain $58 \%$ and $53 \%$ of the biases in the $R_{s}$ trend, respectively, while the biases in the WVP trend can explain only $20 \%$ and $36 \%$ of the biases in the $R_{s}$ trend, respectively. As for the remaining bias, it may be caused by the input of climatological aerosol into the reanalyses. Our result regarding to the contribution of the biases in the TCC trend from ERA-Interim is similar to the
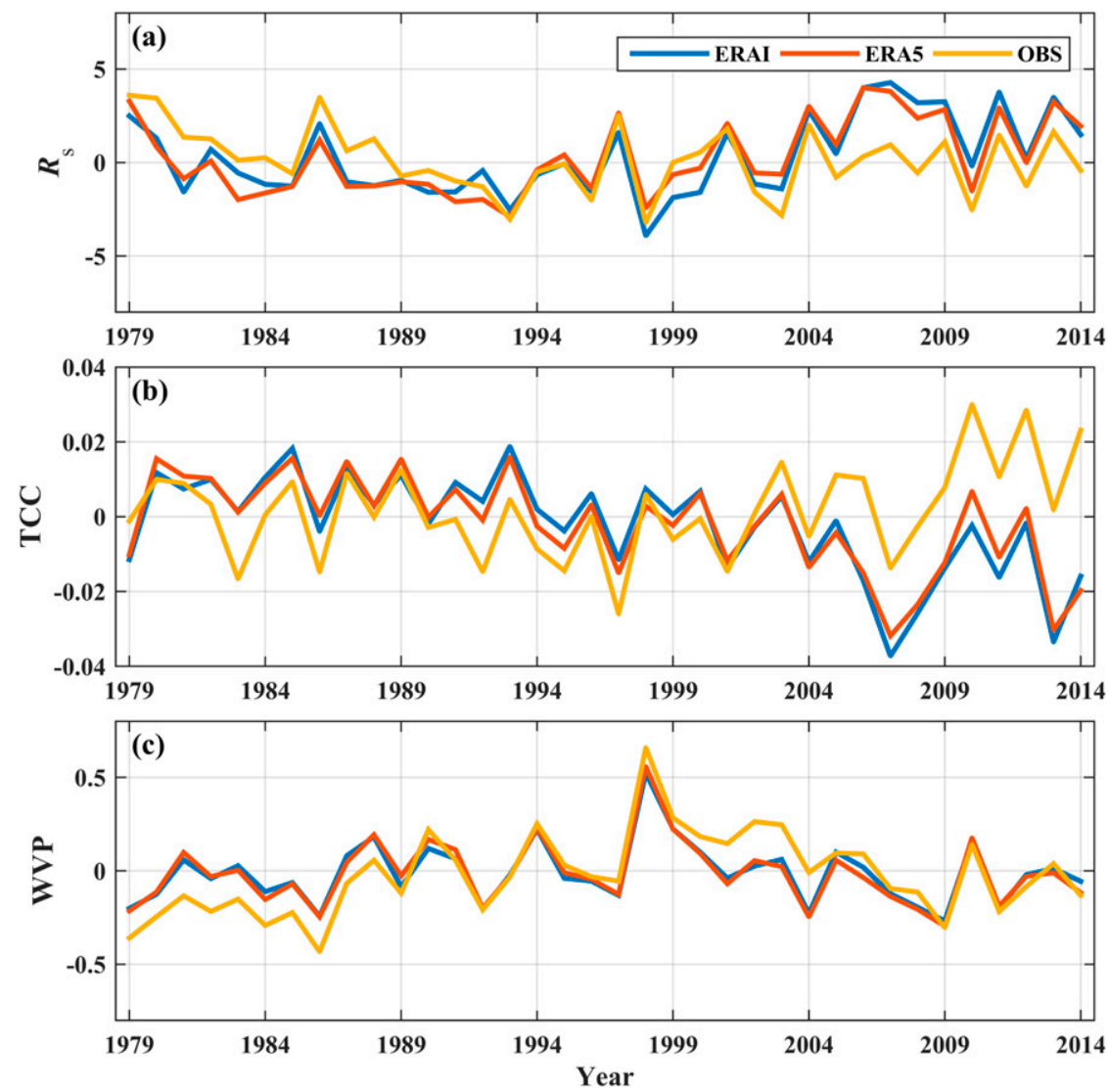

FIG. 10. Time series of the monthly surface incident solar radiation anomaly $\left(R_{s}\right.$; unit: $\mathrm{W} \mathrm{m}^{-2}$ ), total cloud cover (TCC; unit: 1 ), and water vapor pressure (WVP; unit: hPa) from the ground-based observations (OBS; yellow), ERA-Interim (ERAI; blue), and ERA5 (orange) in China from 1979 to 2014. The anomaly is relative to the reference period of 1981-2010. 
TABLE 2. Decadal trends in the $R_{s}$ (unit: $\mathrm{W} \mathrm{m}^{-2}$ decade $^{-1}$ ) and the contributions of TCC and WVP to the $R_{s}$ trend biases in ERAInterim and ERA5 during three periods of 1979-2014, 1979-93, and 1994-2014. The terms $k_{\mathrm{R} s}$ and $\Delta k_{\mathrm{Rs}}$ denote the national mean $R_{s}$ trend and the trend bias in reanalysis compared to the SunDu-derived $R_{s}$ data; $\mathrm{Ct}_{\mathrm{TCC}}$ and $\mathrm{Ct}_{\mathrm{WVP}}$ denote the contributions of TCC and WVP to the $R_{s}$ trend biases in ERA-Interim (ERAI) and ERA5; and $k_{\text {Rclear }}$ denotes the $R_{s}$ trend in the clear-sky condition. The quantities above are calculated using the SunDu-derived $R_{s}$ data and the spatiotemporally collocated reanalysis data. For comparison, $k_{\text {all-grids }}$ denotes the $R_{s}$ trend calculated from the spatially complete ERA-Interim and ERA5 in China. Trends at a significance level of 0.05 are shown in boldface and those at a significance level of 0.1 are in italic.

\begin{tabular}{|c|c|c|c|c|c|c|c|}
\hline Period & & $k_{\mathrm{Rs}}$ & $\Delta k_{\mathrm{Rs}}$ & $\mathrm{Ct}_{\mathrm{TCC}}$ & $\mathrm{Ct}_{\mathrm{WVP}}$ & $k_{\text {Rclear }}$ & $k_{\text {all-grids }}$ \\
\hline \multirow[t]{3}{*}{ 1979-2014 } & OBS & $-0.47 \pm 0.56$ & - & - & - & $-0.11 \pm 0.21$ & - \\
\hline & ERAI & $\mathbf{0 . 8 6} \pm 0.64$ & $\mathbf{1 . 3 3} \pm 0.38$ & $0.77 \pm 0.09$ & $0.27 \pm 0.12$ & $\mathbf{0 . 8 7} \pm 0.42$ & $\mathbf{0 . 7 7} \pm 0.60$ \\
\hline & ERA5 & $\mathbf{0 . 8 9} \pm 0.60$ & $\mathbf{1 . 3 6} \pm 0.31$ & $0.73 \pm 0.06$ & $0.49 \pm 0.07$ & $\mathbf{0 . 9 9} \pm 0.36$ & $\mathbf{0 . 7 6} \pm 0.54$ \\
\hline \multirow[t]{3}{*}{ 1979-93 } & OBS & $\mathbf{- 3 . 3 1} \pm 1.61$ & - & - & - & $-\mathbf{0 . 9 7} \pm 0.70$ & - \\
\hline & ERAI & $-\mathbf{1 . 9 9} \pm 1.56$ & $\mathbf{1 . 3 1} \pm 1.14$ & $0.53 \pm 0.56$ & $0.77 \pm 0.41$ & $-0.37 \pm 0.53$ & $-\mathbf{1 . 6 8} \pm 1.59$ \\
\hline & ERA5 & $-\mathbf{2 . 4 2} \pm 1.53$ & $0.89 \pm 1.09$ & $0.38 \pm 0.16$ & $0.63 \pm 0.38$ & $-0.59 \pm 0.61$ & $-\mathbf{2 . 1 2} \pm 1.67$ \\
\hline \multirow[t]{3}{*}{ 1994-2014 } & OBS & $0.30 \pm 1.28$ & - & - & - & $\mathbf{0 . 9 0} \pm 0.40$ & - \\
\hline & ERAI & $2.26 \pm 1.51$ & $\mathbf{1 . 9 5} \pm 1.00$ & $1.25 \pm 0.12$ & $-0.17 \pm 0.41$ & $\mathbf{1 . 7 1} \pm 1.04$ & $\mathbf{2 . 0 6} \pm 1.38$ \\
\hline & ERA5 & $\mathbf{1 . 4 9} \pm 1.37$ & $\mathbf{1 . 1 9} \pm 0.78$ & $0.73 \pm 0.10$ & $-0.20 \pm 0.31$ & $\mathbf{1 . 4 6} \pm 0.80$ & $\mathbf{1 . 1 9} \pm 1.18$ \\
\hline
\end{tabular}

estimates (58\% vs 54\%) reported by Feng and Wang (2019). The WVP trend biases can explain much more of the biases $(59 \%$ and $71 \%$ of which are from ERA-Interim and ERA5, respectively) in the $R_{s}$ trend from the reanalyses during the period of 1979-93, and the effect of TCC trend biases on $R_{S}(64 \%$ and $61 \%$ of which are from ERA-Interim and ERA5, respectively) is more prominent from 1994 to 2014. In general, due to the improvement of TCC simulation by ERA5, its $R_{s}$ trend bias contributed by the TCC trend bias is less than that of ERA-Interim.
Even though SunDu data have been homogenized, the uncertainties of SunDu data cannot be ignored. For example, the shiftwork of different meteorological observers still may cause problems on the homogeneity of SunDu data because SunDu is recorded by visually reading burned signals on light-sensitive paper (Xu et al. 2011). SunDu-derived $R_{s}$ values in this study have been carefully processed by quality control (He et al. 2018), but there are still unknown uncertainties for the regions with sparse sites, such as the Tibetan Plateau.
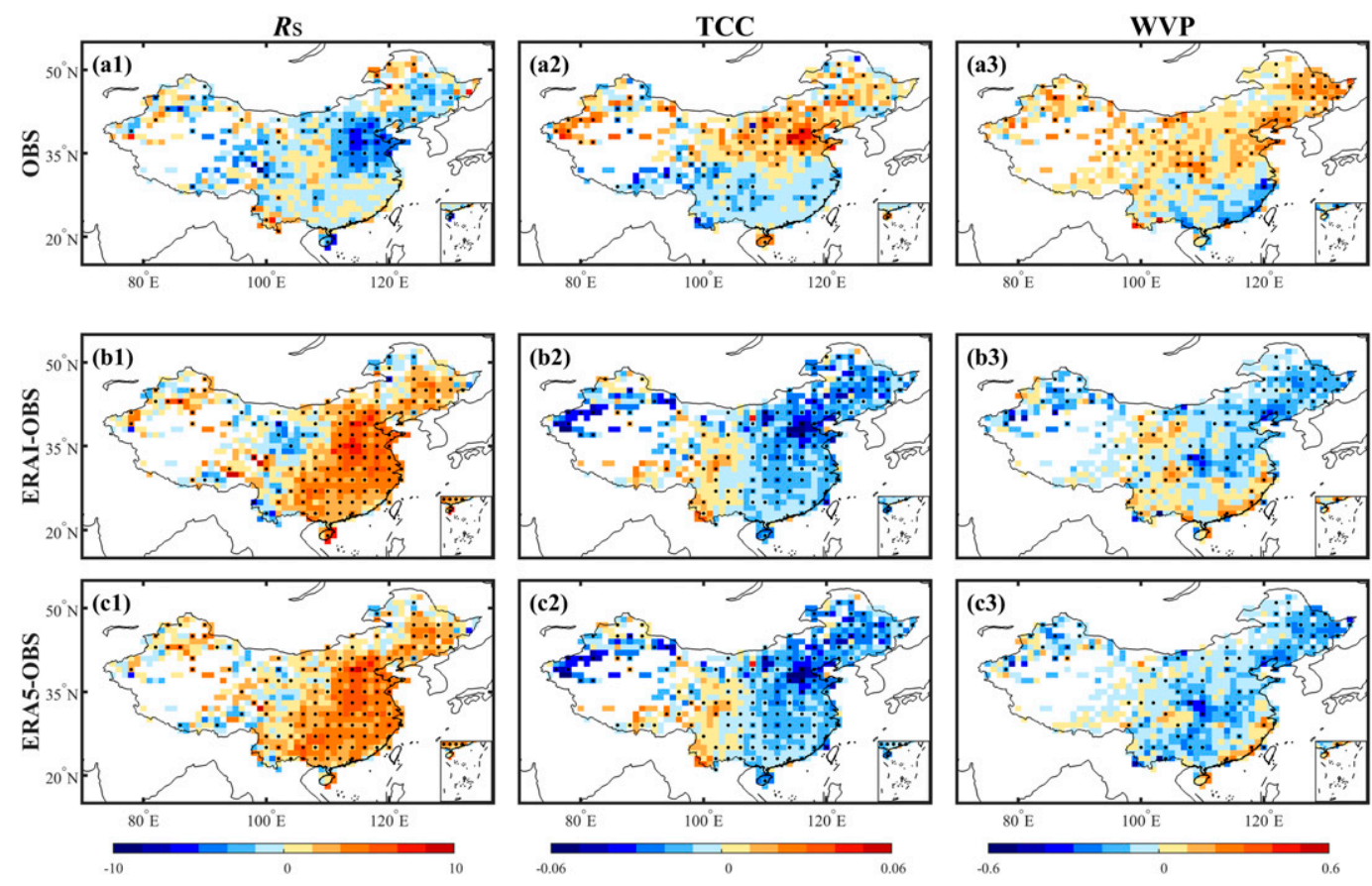

FIG. 11. Spatial distributions of the trend biases in monthly anomaly surface incident solar radiation $\left(R_{s}\right.$, unit: W m ${ }^{-2}$ decade $^{-1}$ ), total cloud cover (TCC; unit: 1 decade $^{-1}$ ), and water vapor pressure (WVP; unit: hPa decade ${ }^{-1}$ ) from ERA-Interim (ERAI) and ERA5 relative to the ground-based observations (OBS) during the period of 1979-2014. (top) Trends of $R_{s}$, TCC, and WVP from the ground-based observations. Black dots denote significant trends $(p<0.05)$. 

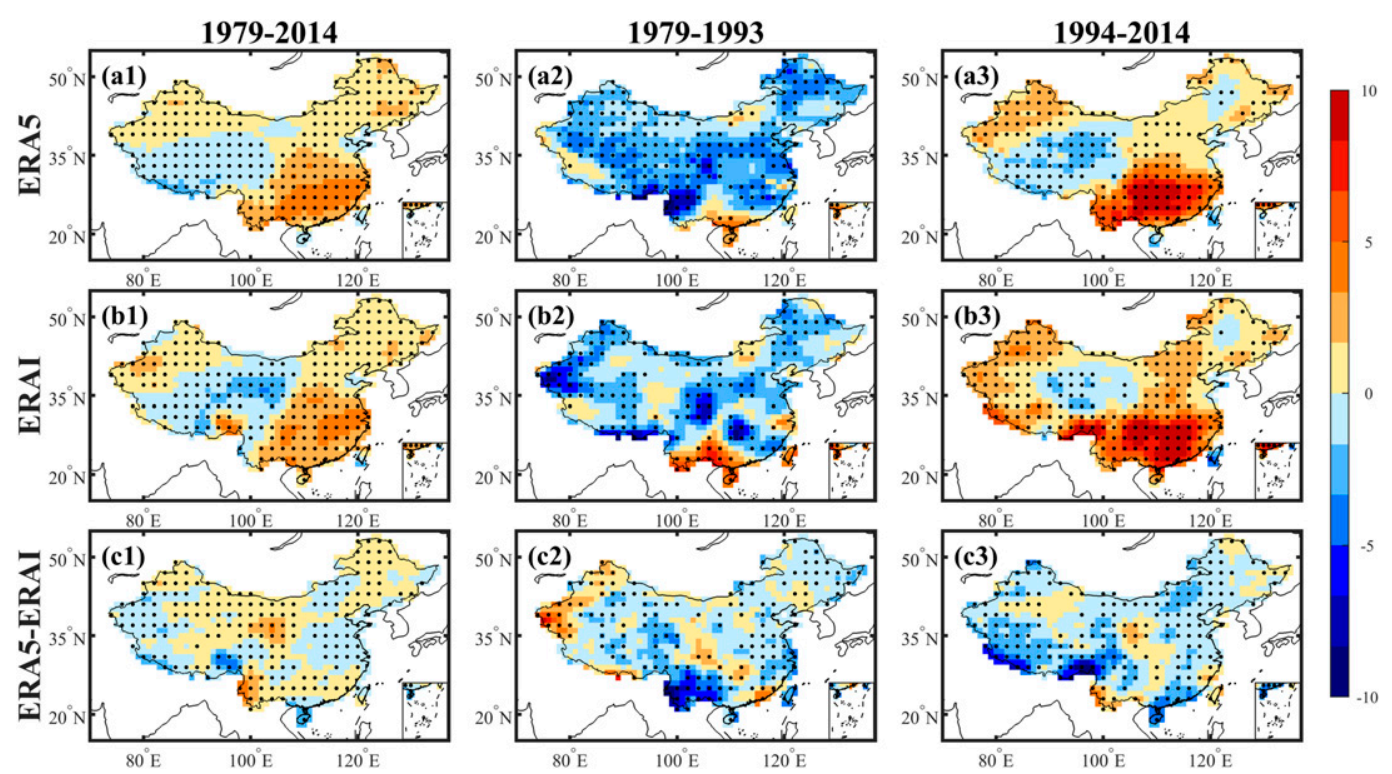

FIG. 12. Spatial distribution of the trends in monthly anomaly surface incident solar radiation $\left(R_{s}\right.$; unit: $\mathrm{W} \mathrm{m}^{-2}$ decade $^{-1}$ ) from the spatially complete ERA5 and ERA-Interim (ERAI) over China during the three periods of 1979-2014, 1979-93, and 1994-2014. (bottom) Trend biases between ERA5 and ERA-Interim. Black dots denote significant trends $(p<0.05)$.

Due to its higher spatiotemporal resolution and the benefits from the intensive development of the data assimilation scheme, the national mean bias is reduced from $15.88 \mathrm{~W} \mathrm{~m}^{-2}$ by ERA-Interim to $10.07 \mathrm{~W} \mathrm{~m}^{-2}$ by ERA5 in simulating the multiyear-average $R_{s}$ over China between the reanalysis products and ground-based observations, which improves the accuracy of TCC estimates. However, ERA5 still cannot accurately reproduce the long-term trend in $R_{s}$. Undoubtedly, these reanalysis products could compensate for the shortcomings of uneven ground-based observations and satellite-based data because of their large and continuous spatial and temporal coverages (Wild and Schmucki 2010; Dee et al. 2011b; Jia et al. 2013; Zhang et al. 2016; Urraca et al. 2018b); however, these reanalyses need to enhance the performance of their related parameterizations, input the variations in aerosols, and consider aerosol-cloud interactions.

Acknowledgments. This study was funded by the National Key R\&D Program of China (2017YFA0603601), the National Natural Science Foundation of China (41930970 and 41525018) and the State Key Laboratory of Earth Surface Processes and Resource Ecology (U2020-KF-02). The authors declare no competing interests. The ERA-Interim and ERA5 data were obtained at https://apps.ecmwf.int/datasets/data/interim-full-daily/ and https://apps.ecmwf.int/data-catalogues/era5/, respectively.

\section{REFERENCES}

Babar, B., R. Graversen, and T. Boström, 2019: Solar radiation estimation at high latitudes: Assessment of the CMSAF databases, ASR and ERA5. Sol. Energy, 182, 397-411, https:/doi.org/ 10.1016/j.solener.2019.02.058.
Berrisford, P., D. Dee, K. Fielding, M. Fuentes, P. Kallberg, S. Kobayashi, and S. Uppala, 2009: The ERA-Interim Archive. ERA Rep. Series 1, 16 pp., https://www.ecmwf.int/en/ elibrary/8173-era-interim-archive.

Bland, J. M., and D. G. Altman, 1996: Statistics notes: Measurement error. BMJ, 312, 1654, https://doi.org/10.1136/bmj.312.7047. 1654.

Dee, D. P., E. Källén, A. Simmons, and L. Haimberger, 2011a: Comments on "Reanalyses suitable for characterizing longterm trends." Bull. Amer. Meteor. Soc., 92, 65-70, https://doi.org/ 10.1175/2010BAMS3070.1.

—, and Coauthors, 2011b: The ERA-Interim reanalysis: Configuration and performance of the data assimilation system. Quart. J. Roy. Meteor. Soc., 137, 553-597, https://doi.org/ 10.1002/qj.828.

ECMWF, 2016: Part II: Data assimilation. IFS Documentation CY41R2, ECMWF, 103 pp. https://www.ecmwf.int/node/16666.

Feng, F., and K. Wang, 2019: Determining factors of monthly to decadal variability in surface solar radiation in China: Evidences from current reanalyses. J. Geophys. Res. Atmos., 124, 91619182, https://doi.org/10.1029/2018JD030214.

Forbes, R. M., and M. Ahlgrimm, 2014: On the representation of high-latitude boundary layer mixed-phase cloud in the ECMWF global model. Mon. Wea. Rev., 142, 3425-3445, https://doi.org/ 10.1175/MWR-D-13-00325.1.

Haywood, J., and O. Boucher, 2000: Estimates of the direct and indirect radiative forcing due to tropospheric aerosols: A review. Rev. Geophys., 38, 513-543, https://doi.org/10.1029/ 1999RG000078.

He, Y., and K. Wang, 2019: Variability in direct and diffuse solar radiation across China from 1958 to 2017. Geophys. Res. Lett., 47, e2019GL084570, https://doi.org/10.1029/2019GL084570.

- _ - C. Zhou, and M. Wild, 2018: A revisit of global dimming and brightening based on the sunshine duration. Geophys. Res. Lett., 45, 4281-4289, https://doi.org/10.1029/2018GL077424. 
Hersbach, H., and D. Dee, 2016: ERA5 reanalysis is in production. ECMWF Newsletter, No. 147, ECMWF, Reading, United Kingdom, 7, https://www.ecmwf.int/sites/default/files/elibrary/ 2016/16299-newsletter-no147-spring-2016.pdf.

_ , and Coauthors, 2019: Global reanalysis: Goodbye ERAInterim, hello ERA5. ECMWF Newsletter, No. 159, ECMWF, Reading, United Kingdom, 17-24, https://www.ecmwf.int/en/ elibrary/19027-global-reanalysis-goodbye-era-interim-helloera5.

Hess, M., P. Koepke, and I. Schult, 1998: Optical properties of aerosols and clouds: The software package OPAC. Bull. Amer. Meteor. Soc., 79, 831-844, https://doi.org/10.1175/15200477(1998)079<0831:OPOAAC > 2.0.CO;2.

Huang, J., L. J. Rikus, Y. Qin, and J. Katzfey, 2018: Assessing model performance of daily solar irradiance forecasts over Australia. Sol. Energy, 176, 615-626, https://doi.org/10.1016/ j.solener.2018.10.080.

Jia, B., Z. Xie, A. Dai, C. Shi, and F. Chen, 2013: Evaluation of satellite and reanalysis products of downward surface solar radiation over East Asia: Spatial and seasonal variations. J. Geophys. Res. Atmos., 118, 3431-3446, https://doi.org/ 10.1002/jgrd.50353.

Kalnay, E., and M. Cai, 2003: Impact of urbanization and land-use change on climate. Nature, $\mathbf{4 2 3}$, 528-531, https://doi.org/10.1038/ nature 01675 .

Kennedy, A. D., X. Dong, B. Xi, S. Xie, Y. Zhang, and J. Chen, 2011: A comparison of MERRA and NARR reanalyses with the DOE ARM SGP data. J. Climate, 24, 4541-4557, https:// doi.org/10.1175/2011JCLI3978.1.

Li, J., C. Li, C. Zhao, and T. Su, 2016: Changes in surface aerosol extinction trends over China during 1980-2013 inferred from quality-controlled visibility data. Geophys. Res. Lett., 43, 8713-8719, https://doi.org/10.1002/2016GL070201.

Morcrette, J., H. W. Barker, J. Cole, M. J. Iacono, and R. Pincus, 2008: Impact of a new radiation package, McRad, in the ECMWF Integrated Forecasting System. Mon. Wea. Rev., 136, 4773-4798, https://doi.org/10.1175/2008MWR2363.1.

Muneer, T., and M. Gul, 2000: Evaluation of sunshine and cloud cover based models for generating solar radiation data. Energy Convers. Manage., 41, 461-482, https://doi.org/10.1016/S01968904(99)00108-9.

Sanchez-Romero, A., A. Sanchez-Lorenzo, J. Calbó, J. González, and C. Azorin-Molina, 2014: The signal of aerosol-induced changes in sunshine duration records: A review of the evidence. J. Geophys. Res. Atmos., 119, 4657-4673, https:// doi.org/10.1002/2013JD021393.

Shi, G.-Y., and Coauthors, 2008: Data quality assessment and the long-term trend of ground solar radiation in China. J. Appl. Meteor. Climatol., 47, 1006-1016, https://doi.org/ 10.1175/2007JAMC1493.1.

Smith, C. J., J. M. Bright, and R. Crook, 2017: Cloud cover effect of clear-sky index distributions and differences between human and automatic cloud observations. Sol. Energy, 144, 10-21, https://doi.org/10.1016/j.solener.2016.12.055.

Stanhill, G., and S. Cohen, 2001: Global dimming: A review of the evidence for a widespread and significant reduction in global radiation with discussion of its probable causes and possible agricultural consequences. Agric. For. Meteor., 107, 255-278, https://doi.org/10.1016/S0168-1923(00)00241-0.

Tang, W. J., K. Yang, J. Qin, C. C. K. Cheng, and J. He, 2011: Solar radiation trend across China in recent decades: A revisit with quality-controlled data. Atmos. Chem. Phys., 11, 393-406, https://doi.org/10.5194/acp-11-393-2011.
Thorne, P. W., and R. S. Vose, 2010: Reanalyses suitable for characterizing long-term trends: Are they really achievable? Bull. Amer. Meteor. Soc., 91, 353-362, https://doi.org/10.1175/ 2009BAMS2858.1.

Urraca, R., T. Huld, F. J. Martinez-de-Pison, and A. Sanz-Garcia, 2018a: Sources of uncertainty in annual global horizontal irradiance data. Sol. Energy, 170, 873-884, https://doi.org/ 10.1016/j.solener.2018.06.005.

$\longrightarrow,-$, A. Gracia-Amillo, F. Javier Martinez-de-Pison, F. Kaspar, and A. Sanz-Garcia, 2018b: Evaluation of global horizontal irradiance estimates from ERA5 and COSMO-REA6 reanalyses using ground and satellite-based data. Sol. Energy, 164, 339-354, https://doi.org/10.1016/j.solener.2018.02.059.

Wang, H., F. Sun, and W. Liu, 2018: Spatial and temporal patterns as well as major influencing factors of global and diffuse horizontal irradiance over China: 1960-2014. Sol. Energy, 159, 601-615, https://doi.org/10.1016/j.solener.2017.11.038.

Wang, K., 2014: Measurement biases explain discrepancies between the observed and simulated decadal variability of surface incident solar radiation. Sci. Rep., 4, 6144, https://doi.org/ 10.1038/srep06144.

— , Q. Ma, Z. Li, and J. Wang, 2015: Decadal variability of surface incident solar radiation over China: Observations, satellite retrievals, and reanalyses. J. Geophys. Res. Atmos., 120, 6500-6514, https://doi.org/10.1002/2015JD023420.

Wang, X. L., H. Chen, Y. Wu, Y. Feng, and Q. Pu, 2010: New techniques for the detection and adjustment of shifts in daily precipitation data series. J. Appl. Meteor. Climatol., 49, 24162436, https://doi.org/10.1175/2010JAMC2376.1.

Wang, X. Y., R. E. Dickinson, L. Su, C. Zhou, and K. Wang, 2018: PM2.5 pollution in China and how it has been exacerbated by terrain and meteorological conditions. Bull. Amer. Meteor. Soc., 99, 105-119, https://doi.org/10.1175/BAMS-D-16-0301.1.

Wang, Y., and M. Wild, 2016: A new look at solar dimming and brightening in China. Geophys. Res. Lett., 43, 11777-11785, https://doi.org/10.1002/2016GL071009.

Wild, M., 2009: Global dimming and brightening: A review. J. Geophys. Res., 114, D00D16, https://doi.org/10.1029/ 2008JD011470.

_ 2016 : Decadal changes in radiative fluxes at land and ocean surfaces and their relevance for global warming. Wiley Interdiscip. Rev.: Climate Change, 7, 91-107, https://doi.org/10.1002/wcc.372. _ and E. Schmucki, 2010: Assessment of global dimming and brightening in IPCC-AR4/CMIP3 models and ERA40. Climate Dyn., 37, 1671-1688, https://doi.org/10.1007/s00382-010-0939-3.

Xia, X., P. Wang, H. Chen, and F. Liang, 2006: Analysis of downwelling surface solar radiation in China from National Centers for Environmental Prediction reanalysis, satellite estimates, and surface observations. J. Geophys. Res., 111, D09103, https://doi.org/10.1029/2005JD006405.

$\mathrm{Xu}$, J., K. Masuda, Y. Ishigooka, T. Kuwagata, S. Haginoya, T. Hayasaka, and T. Yasunari, 2011: Estimation and verification of daily surface shortwave flux over China. J. Meteor. Soc. Japan, 89A, 225-238, https://doi.org/10.2151/jmsj.2011-A14.

Yang, K., G. W. Huang, and N. Tamai, 2001: A hybrid model for estimating global solar radiation. Sol. Energy, 70, 13-22, https://doi.org/10.1016/S0038-092X(00)00121-3.

— - T. Koike, and B. S. Ye, 2006: Improving estimation of hourly, daily, and monthly solar radiation by importing global data sets. Agric. For. Meteor., 137, 43-55, https://doi.org/10.1016/ j.agrformet.2006.02.001.

__ B. B. Ding, J. Qin, W. Tang, N. Lu, and C. Lin, 2012: Can aerosol loading explain the solar dimming over the Tibetan 
Plateau? Geophys. Res. Lett., 39, L20710, https://doi.org/ 10.1029/2012GL053733.

Yang, S., X. L. Wang, and M. Wild, 2018: Homogenization and trend analysis of the 1958-2016 in situ surface solar radiation records in China. J. Climate, 31, 4529-4541, https://doi.org/ 10.1175/JCLI-D-17-0891.1.

- ——, and — 2019: Causes of dimming and brightening in China inferred from homogenized daily clear-sky and all-sky in situ surface solar radiation records (1958-2016). J. Climate, 32, 5901-5913, https://doi.org/10.1175/JCLI-D-18-0666.1.

You, Q., A. Sanchez-Lorenzo, M. Wild, D. Folini, K. Fraedrich, G. Ren, and S. Kang, 2013: Decadal variation of surface solar radiation in the Tibetan Plateau from observations, reanalysis and model simulations. Climate Dyn., 40, 2073-2086, https:// doi.org/10.1007/s00382-012-1383-3.

Zhang, X., S. Liang, G. Wang, Y. Yao, B. Jiang, and J. Cheng, 2016: Evaluation of the reanalysis surface incident shortwave radiation products from NCEP, ECMWF, GSFC, and JMA using satellite and surface observations. Remote Sens., 8, 225, https:// doi.org/10.3390/rs8030225.

Zhao, C., Y. Chen, J. Li, H. Letu, Y. Su, T. Chen, and X. Wu, 2019: Fifteen-year statistical analysis of cloud characteristics over
China using Terra and Aqua Moderate Resolution Imaging Spectroradiometer observations. Int. J. Climatol., 39, 26122629, https://doi.org/10.1002/joc.5975.

Zhao, L., X. Lee, and S. Liu, 2013: Correcting surface solar radiation of two data assimilation systems against FLUXNET observations in North America. J. Geophys. Res. Atmos., 118, 9552-9564, https://doi.org/10.1002/jgrd.50697.

Zhou, C., and K. Wang, 2016: Evaluation of surface fluxes in ERAInterim using flux tower data. J. Climate, 29, 1573-1582, https://doi.org/10.1175/JCLI-D-15-0523.1.

,-- , and Q. Ma, 2017: Evaluation of eight current reanalyses in simulating land surface temperature from 1979 to 2003 in China. J. Climate, 30, 7379-7398, https://doi.org/10.1175/JCLID-16-0903.1.

-, Y. He, and K. Wang, 2018: On the suitability of current atmospheric reanalyses for regional warming studies over China. Atmos. Chem. Phys., 18, 8113-8136, https://doi.org/ 10.5194/acp-18-8113-2018.

Zhu, J., H. Che, X. Xia, X. Yu, and J. Wang, 2019: Analysis of water vapor effects on aerosol properties and direct radiative forcing in China. Sci. Total Environ., 650, 257-266, https://doi.org/ 10.1016/j.scitotenv.2018.09.022. 